\title{
Nonlinear Thermal and Structural Analysis MASTEP of a Brazed Solar-Central-Receiver Panel
}

L. M. Napolitano, Jr., M. P. Kanouff

\begin{abstract}
Prepared by Sandia National Laboratories, Albuquerque, New
Mexico 87185 and Livermore, California 94550 for the United

States Department of Energy under Contract DE-AC04-76DP00789.
\end{abstract}

Printed July 1981
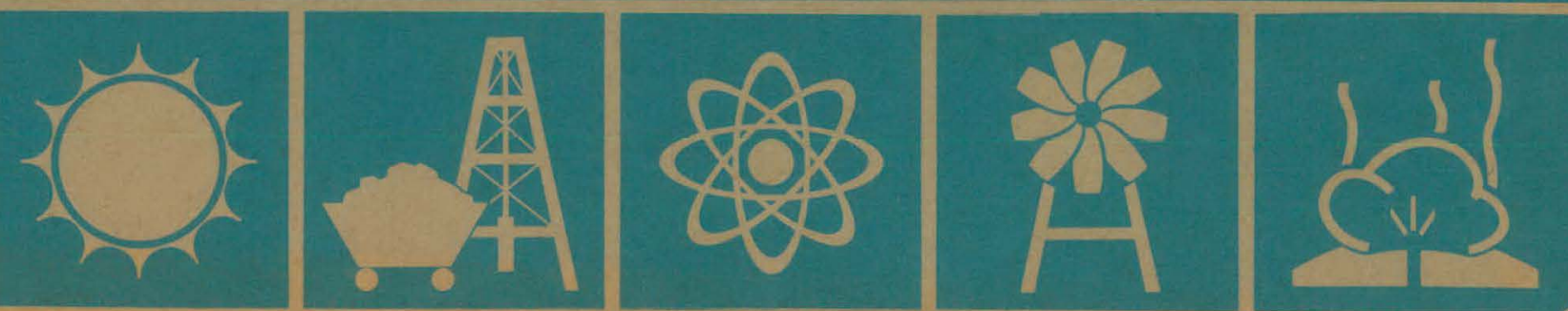


\section{DISCLAIMER}

This report was prepared as an account of work sponsored by an agency of the United States Government. Neither the United States Government nor any agency Thereof, nor any of their employees, makes any warranty, express or implied, or assumes any legal liability or responsibility for the accuracy, completeness, or usefulness of any information, apparatus, product, or process disclosed, or represents that its use would not infringe privately owned rights. Reference herein to any specific commercial product, process, or service by trade name, trademark, manufacturer, or otherwise does not necessarily constitute or imply its endorsement, recommendation, or favoring by the United States Government or any agency thereof. The views and opinions of authors expressed herein do not necessarily state or reflect those of the United States Government or any agency thereof. 


\section{DISCLAIMER}

Portions of this document may be illegible in electronic image products. Images are produced from the best available original document. 


\section{NOTICE}

This report was prepared as an account of work sponsored by the United States Government. Neither the United States nor the United States Department of Energy, nor any of their employees, makes any warranty, express or implied, or assumes any legal liability to responsibility for the accuracy, completeness or usefulness of any information, apparatus, product or process disclosed, or represents that its use would not infringe privately owned rights.

Printed in the United States of America

Available from

National Technical Information Service

U. S. Department of Commerce

5285 Port Royal Road

Springfield, VA 22161

Price: Printed Copy $\$ 7.25$; Microfiche $\$ 3.00$ 


\section{PAGES 1 to 2 WERE INTENTIONALLY LEFT BLANK}


SAND81-8017

Unl imited Release

Printed July 1981

NONLINEAR THERMAL AND STRUCTURAL ANALYSIS

OF A BRAZED SOLAR-CENTRAL-RECEIVER PÄNEL

L. M. Napol itano, Jr.

Applied Mechanics Division

M. P. Kanouff

Thermal Sciences Division

Sandia National Laboratories, Livermore

\section{ABSTRACT}

Sandia has been evaluating an alternative central receiver that uses molten sodium as the transfer medium. The receiver is composed of panels of tubes, heated on one side by concentrated solar flux, through which the molten sodium flows. Because the tubes are constrained from bending, the thermal gradients induce stresses and strains that have the potential to reduce the desired panel lifetime of 30 years.

One part of the evaluation program was to be a test of a reduced-scale panel at Sandia's Central Receiver Test Facility in Albuquerque. The panel incorporates a new way of joining tubes--brazing to intermediate filler strips-which can affect the panel's lifetime. To calculate the stresses and strains for the worst-case section of the experimental panel, we have done a nonl inear elastic-plastic analysis with the MARC finite element computer code, which takes the temperature dependence of the material properties into account. From the results are predicted tube design lifetimes. The analysis shows that concerns for cracking and reduction in lifetime are warranted, but a more detailed fracture analysis is necessary to determine whether there is a stable-crack-growth problem.

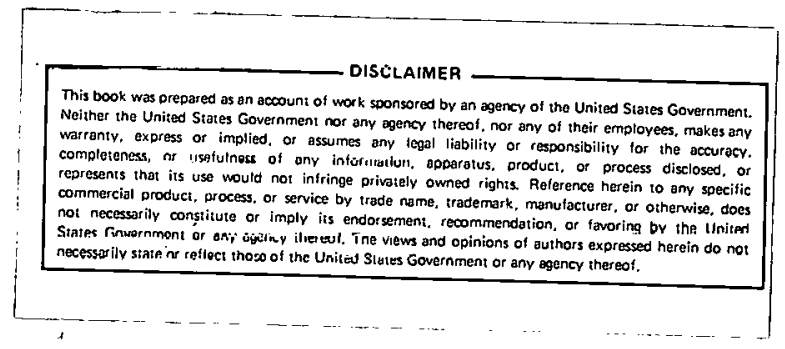

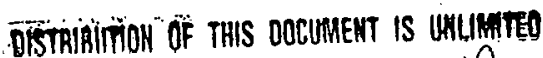


CONTENTS

Page

Introduction $\quad \cdot \quad 9$

Conclusions $\quad 10$

Panel Configuration and Environment $\quad 10$

Stress-Strain Calculations 13

Thermal-Hydraulic Analysis $\quad 13$

Linear Crown Strain Analysis $\quad 16$

Thermal Finite Element Analysis $\quad 17$

$\begin{array}{ll}\text { Structural Finite Element Analysis } & 20\end{array}$

Stress-Strain Results . . . $\quad 26$

Discussion $\quad 32$

Fatigue-Life Calculations 32

Idealized Structural Model

Error Analysis $\quad 34$

APPENDIX--EXAMPLES OF GRAPHICAL RESULTS 37

REFERENCES $\quad \cdot \quad 49$ 


\section{ILLUSTRATIONS}

No.

Page

1 Receiver Panel Dimensioned for SRE $\quad 10$

2 90-mil and 30-mil Full Hourglasses in Place between Tubes 11

3 90-mil and 30-mil Half Hourglasses in Place between. Tubes 12

4 Modelled vs Actual Hourglass and Braze $\quad \ldots \quad 12$

5 Modification to THERMAL-HYDRAULIC Model to Account for Hourglasses 15

6 TUBEBND Sample.Analysis Output 16

7 Finite-Element Mesh for 30-mil Full Hourglass MARC Thermal Analyses 18

8 Temperature Profiles for 30-mil Full Hourglass under High Flux 19

9 Effective Cavity between Tubes $\quad 20$

10 Finite-Element Mesh for 30-mil Full Hourglass MARC Stress Analysis 22

11 Location of Assumed Symmetry Lines 23

12 Material Properties for Stress Analysis 24

13 Model of Material Stress-Strain Behavior 25

14 Placement of Gap Link Elements 26

15 Transverse and Shear Stresses along Uncracked Braze (Front Quarter) . 29

16 Transverse and Shear Stresses along. One-Element Cracked Braze 29

17 Transverse and Shear Stresses along Two-Element Cracked Braze 30

18 Transverse and Shear Stresses along Three-Element Cracked Braze 30

19 Transverse and Shearr Stresses along. Four-Element Cracked Braze 31

20 Transverse and Shear Stresses along Five-Element Cracked Braze 31

21 Evolution of Shear Stress along Braze during Sequential Crack 32 Opening 


\section{TABLES}

No.

Page

I Thermal-Hydraulic Inputs $\quad 14$

II MARC Thermal Finite-Element Analysis Inputs $\quad 18$

III TACO Thermal Finite-Element Analysis Inputs . . . 21

IV Geometric and Flux, Cases Analyzed 21

V Equivalent Strains $\quad 27$

$\begin{array}{lrr}\text { VI Braze Loads } & 28\end{array}$

VII ASME N-47 Design Lifetime Cycles $\quad 33$ 
NONLINEAR THERMAL AND STRUCTURAL ANALYSIS

OF A BRAZED SOLAR CENTRAL RECEIVER PANEL

Introduction

The solar central receiver concept embodies a field of sun-tracking mirrors (heliostats) that reflect the incoming solar radiation towards a receiver atop a centrally located tower. The concentrated solar flux is absorbed by a working fluid flowing through panels in the receiver, and the thermal energy is transported to its intended use, such as the thermal source for a turbine steam generator. In the overall design of the receiver the structural lifetime of the receiver panels is a primary concern. Fatigue degradation and stress concentrations generated by geometric and/or material discontinuities can significantly reduce the expected lifetime.

Sandia has been evaluating an alternative central receiver design with molten sodium flowing through panels made up of tubes brazed together. The current design has an external receiver configuration with only one-sided heating of the receiver panel tubes. The one-sided heating; together with the high flux levels allowed by the molten sodium, generates large thermal gradients across the tubes. Since the tubes are restrained from bending by supports, the thermal gradients induce thermal stresses. The concern is that these stresses and joint stresses will reduce the desired panel lifetime (30 years). This analysis was requested to clarify this concern.

Specifically, the analysis is a nonlinear elastic-plastic analysis using the MARC finite element code with temperature-dependent material properties. It is applied to a single reduced-scale panel (system research experiment or SRE panel) that was designed to verify the proposed sodium loop system and that was to be tested at Sandia's Central Receiver Test Facility (CRTF) in Albuquerque. The analysis is intended to identify (a) any problems which might occur during the first-cycle power-up or the 3-4-month SRE panel test program, and (b) any lifetime concerns for a full-sized receiver.

The output of the analysis consists of stresses and strains at certain points in a "worst case" section of the SRE panel center tube. From these are produced predicted tube design lifetimes based on the inelastic design curves of the ASME Boiler and Pressure Vessel Code--Code Case $1592(\mathrm{~N}-47)$. While these curves are generally considered conservative, the equivalent strain derived to enter them illuminates troublesome areas in the design. The problem areas are identified and their morphology examined. 
- The analysis shows that serious concerns are warranted about the lifetime performance of the SRE receiver panel design. The stresses on the braze front corner are high and may be intolerable over the life of the panel. If a crack does form, the stress peak follows the crack tip. A detailed fracture analysis will be necessary to determine whether this is a stable crack growth problem. The hourglass-shaped inserts, to which the panel tubes are brazed, have a negative impact on the tube wall life near the joint. Continuous joining systems which occur in the irradiated area are probably inferior to designs which are not exposed, excepting that large amounts of continuous material on the cool side of the tubes increase tube crown strain. The lifetimes calculated from ASME N-47 are too small, but it is our position that the ASME rules are only estimates for fatigue life analysis. Nonetheless, serious questions remain about the integral survivability of this receiver panel.

\section{Panel Configuration and Environment}

Figure 1 shows the entire panel dimensioned for the SRE. The brazing of tubes together to form a monolithic panel is facilitated by placing between the tubes hourglass-shaped inserts that extend the entire length of the irradiated area. At the top and bottom of the panel the tubes, unconstrained by the hourglass and braze, follow a serpentine pattern into the header manifolds. The primary concerns in the analysis were the stresses on the braze and the cyclic strains of the irradiated areas.

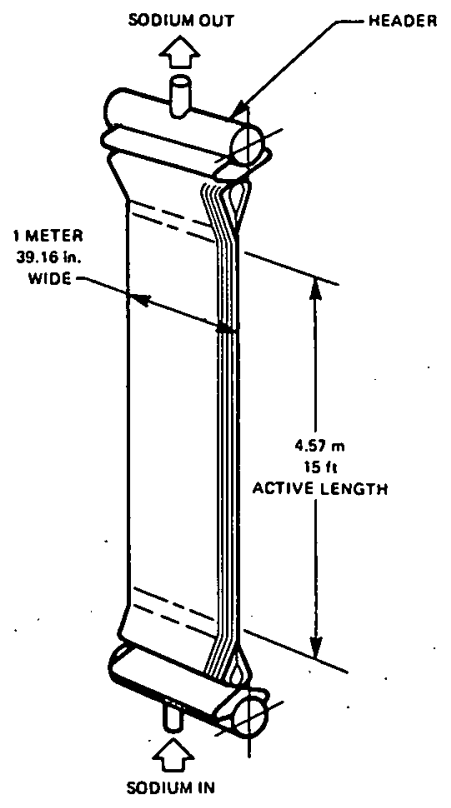

Figure 1. Receiver Panel Dimensioned for SRE 
The length of each hourglass strip and its braze is $4.6 \mathrm{~m}(15 \mathrm{ft})$; the hourglasses extend $+30^{\circ}$ from panel lateral centerline. There are two sizes, one with a minimum thickness of $0.76 \mathrm{~mm}(0.030 \mathrm{in.})$ and one with a minimum thickness of $2.29 \mathrm{~mm}(0.090 \mathrm{in.})$, hereafter identified as the 30-mi 1 and 90-mil hourglasses, respectively (see Figure 2). The design calls for only a few of the 90-mil hourglasses, dispersed across the panel, for instrumentation purposes. The tubes and hourglass inserts are made of Incoloy 800 , plated with nickel to facilitate brazing. Between each hourglass and tube is a $0.038-\mathrm{mm}$ (1.5-mil) braze extending from the front to the back of the hourglass, forming small fillets in the front and back corners. The braze material is Amdry 939 ( $19 \% \mathrm{Mn}, 6 \% \mathrm{Si}, 4 \% \mathrm{Cu}, 0.5 \% \mathrm{~B}$, balance $\mathrm{Ni})$.

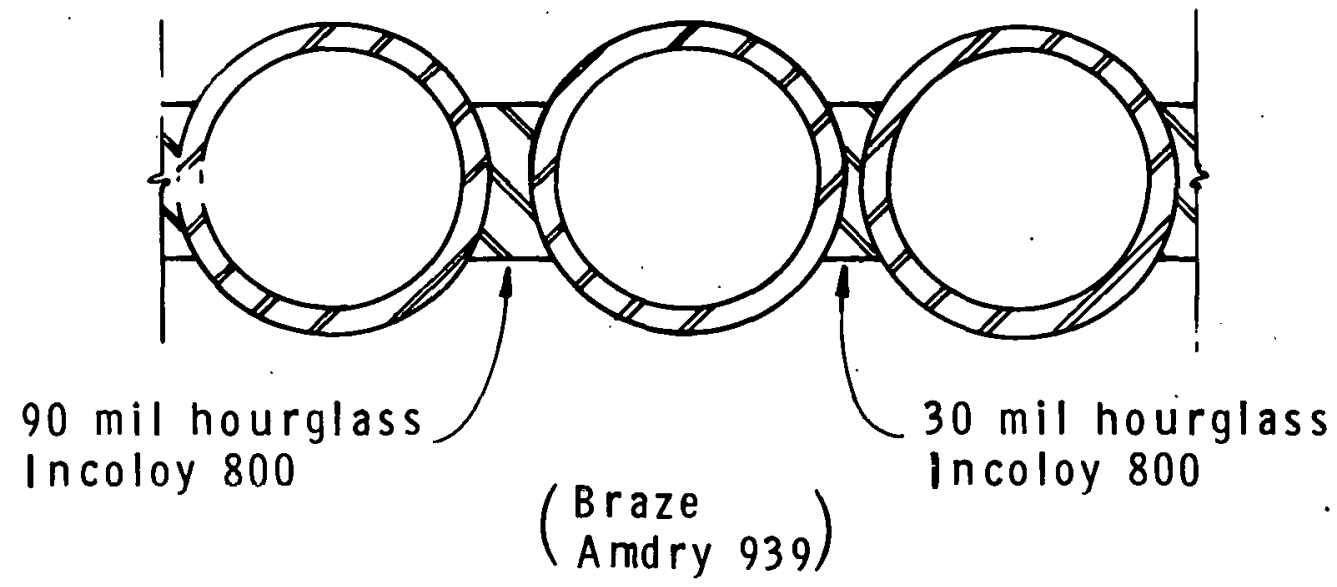

Figure 2. 90-mil and 30-mil Full Hourglasses in Place between Tubes

To reduce high temperatures generated at the front of an hourglass, several alternative designs have been suggested. Most prominent among these are the "half hourglass" designs shown in Figure 3. These would be made by cutting the prefabricated hourglass in half. The small braze fillets at the front and back of the half hourglasses would be similar to those for the full hourglasses. 


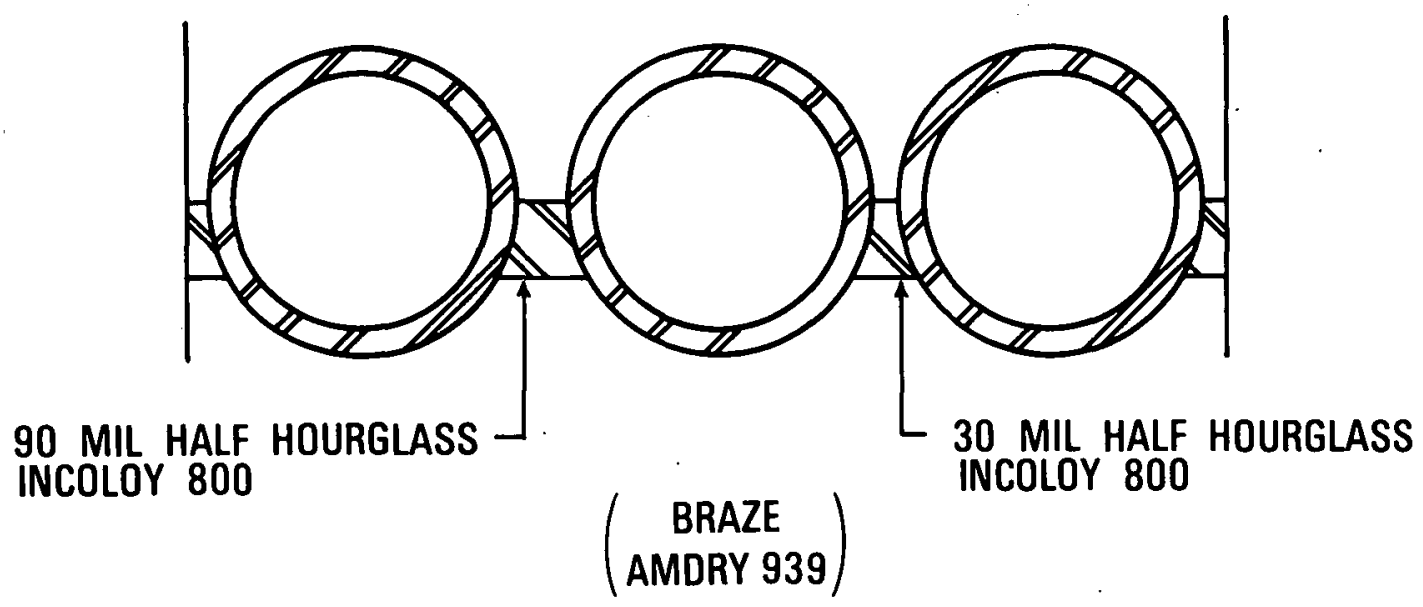

Figure 3. 90-mil and 30-mil Half Hourglasses in Place between Tubes

The analysis assumes that the hourglasses and half hourglasses were "perfect," with flat front and back surfaces and sharp corners. The actual hourglasses manufactured for constructing the SRE panel are shaped more like dogbones (see Figure 4). The effect of the actual hourglasses on the results of the analysis is discussed later.

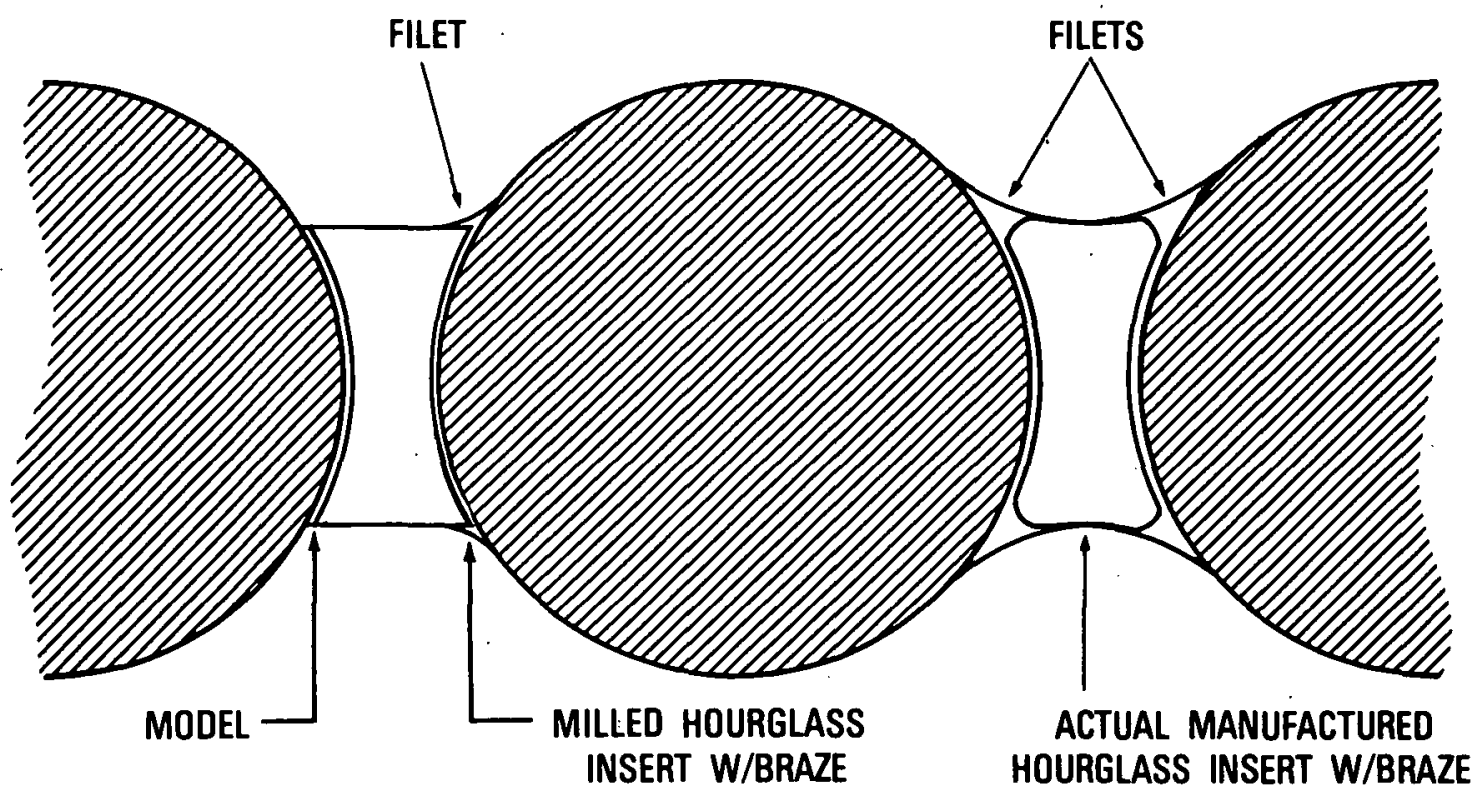

Figure 4. Modelled vs Actual Hourglass and Braze 
The environment the panel was designed to operate in consists of one-sided heating by the redirected solar flux, an insulated back, and specified inlet and outlet sodium temperatures. Two flux levels were considered, a low flux with a peak of $0.64 \mathrm{MW} / \mathrm{m}^{2}\left(202,900 \mathrm{Btu} / \mathrm{h} \mathrm{ft}^{2}\right)$ and a high flux with a peak of $1.5 \mathrm{MW} / \mathrm{m}^{2}\left(475,600 \mathrm{Btu} / \mathrm{h} \mathrm{ft}{ }^{2}\right)$. The inlet bulk sodiuiil temperature was $316^{\circ} \mathrm{C}\left(600^{\circ} \mathrm{F}\right)$, the outlet temperature $593^{\circ} \mathrm{C}\left(1100^{\circ} \mathrm{F}\right)$.

\section{Stress-Strain Calculations}

The analysis addresses several specific concerns about the design including the actual stress state and possible lifetime reductions. Stresses at both braze front and back were generated to understand the susceptiblity of the braze to cracking. While the majority of the braze is expected to be relatively ductile, the small unavoidable fillets at the front and back of the braze will consist of multiphasic braze material which will be extremely brittle and laced with pre-initiated cracks. These points are located at a structural discontinuity, and thus compounding the problem are stress concentrations at the flawed areas. A crack was placed in the model to study its effect on the stress state.

The stress-strain analysis was based on locating the worst section of the worst tube and analyzing that section in detail. The analytical procedure was broken down into four steps: (1) A thermal-hydraulic analysis was done for several tubes to predict the temperature of the sodium through the tubes and the net absorbed thermal power. (2) This temperature distribution was applied to a linear crown-strain model representing a tube on its supports, and an approximation of the tube crown strain along the axis of the tube was generated. (3) At the location of highest combined crown temperature and crown strain a two-dimensional thermal finite element model was constructed that represented a section through the tube and a connecting hourglass. And (4) with the resulting detailed temperature profile through the section, an elastic-plastic generalized plane-strain finite element structural model was used to calculate the resulting stresses and strains. At each step of the analysis, the specified parameters were adjusted and their effects on the analysis were observed. of particular importance were changes in the flux distribution and the material stress-strain behavior, and the influence of a crack in the braze. A more detailed description of the analysis and parameter sensitivity studies follows below.

Thermal-Hydraulic Analysis

This analysis established the boundary conditions at the sections where the finite element analyses were conducted. It required the input flux conditions, including the lateral and vertical distribution normalized to the two peak fiux levels, the inlet and outlet manifold sodium temperatures, and the mass flow rate dm/dt. For ease of analysis the back side of the panel was assumed to be perfectly insulated (calculations have shown that back-side heat loss is negligible). 
The thermal-hydraulic analysis was conducted using SNLL's in-house computer program THERMAL-HYDRAULIC. The program analyzes a single tube; it assumes a cosine distribution of incoming flux, corresponding cosine distribution of losses, and an insulated back. The thermal properties of the tube are assumed fixed, but the properties of the fluid are temperature dependent. Table I gives the values used in this analysis. THERMAL-HYDRAULIC divides the tube vertically into nodes, lumps the incoming flux and losses (including convection and radiation), and calculates a bulk fluid temperature and fiuid film coefficient. Since the losses depend on the exterior surface temperature at the tube, the program iterates the solution until there is agreement between the calculated losses based on the tube surface temperatures and the difference between the incoming flux and the net energy transmitted to the fluid.

TABLE I

THERMAL-HYDRAULIC INPUTS

\begin{tabular}{|c|c|}
\hline Tube irradiated length & $4.57 \mathrm{~m}(15.0 \mathrm{ft})$ \\
\hline Number of nodes along tube & 30 \\
\hline $\begin{array}{l}\text { Absortivity a } \\
\text { (assuming a Pyromark coating) }\end{array}$ & 0.95 \\
\hline $\begin{array}{l}\text { Emissivity } \varepsilon \\
\text { (assuming Pyromark coating) }\end{array}$ & 0.90 \\
\hline Fluid inlet temperature & $316^{\circ} \mathrm{C}\left(600^{\circ} \mathrm{F}\right)$ \\
\hline Fluid inlet pressure & $0.517 \mathrm{MPa}$ (75 psi) \\
\hline Mass flow rate per tube & $470.4 \mathrm{~kg} / \mathrm{h}(1037.1 \mathrm{lb} / \mathrm{h})$ \\
\hline External film coefficient & 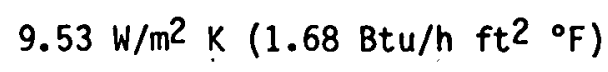 \\
\hline Tube wall conductivity & $19.9 \mathrm{~W} / \mathrm{m}^{2} \mathrm{~K}\left(11.5 \mathrm{Btu} / \mathrm{h} \mathrm{ft}{ }^{2}{ }^{\circ} \mathrm{F}\right)$ \\
\hline Ambient temperature & $21^{\circ} \mathrm{C}\left(70^{\circ} \mathrm{F}\right)$ \\
\hline High applied flux & $1.5 \mathrm{MW} / \mathrm{m}^{2}\left(475,600 \mathrm{Btu} / \mathrm{h} \mathrm{ft} \mathrm{ft}^{2}\right)$ \\
\hline $\begin{array}{l}\text { High applied flux increased for } \\
\text { presence of } 30 \mathrm{mil} \text { hourglass }\end{array}$ & $1.56 \mathrm{MW} / \mathrm{m}^{2}\left(494,600 \mathrm{Btu} / \mathrm{h} \mathrm{ft}{ }^{2}\right)$ \\
\hline $\begin{array}{l}\text { High applied flux increased for } \\
\text { presence of } 90 \mathrm{mil} \text { hourglass }\end{array}$ & $1.62 \mathrm{MW} / \mathrm{m}^{2}\left(513,650 \mathrm{Btu} / \mathrm{h} \mathrm{\textrm {ft } ^ { 2 } )}\right.$ \\
\hline Low applied flux & $0.64 \mathrm{MW} / \mathrm{m}^{2}\left(202,900 \mathrm{Btu} / \mathrm{h} \mathrm{\textrm {ft } ^ { 2 } )}\right.$ \\
\hline $\begin{array}{l}\text { Low applied flux increased for } \\
\text { presence of } 30 \mathrm{mil} \text { hourglass }\end{array}$ & $0.665 \mathrm{MW} / \mathrm{m}^{2}\left(211,000 \mathrm{Btu} / \mathrm{h} \mathrm{ft}^{2}\right)$ \\
\hline $\begin{array}{l}\text { Low applied flux increased for } \\
\text { presence of } 90 \mathrm{mil} \text { hourglass }\end{array}$ & $0.691 \mathrm{MW} / \mathrm{m}^{2}(219,100 \mathrm{Btu} / \mathrm{h} \mathrm{ft} 2)$ \\
\hline
\end{tabular}


To calculate the tube surface temperature for the given assumptions (cosine distribution of net absorbed flux, insulated back), an exact analytical solution for the temperature profile was used that was based on a Fourier series representation of the heat flux and temperature around and through the tube wa11. The output from THERMAL-HYDRAULIC was the net absorbed flux at the nodes, the bulk fluid temperature, and assorted thermal-hydraulic parameters (efficiency, film coefficient, pressure, etc.).

It was necessary to make some adjustments and corrections to account for differences between the receiver panel tubes being analyzed and the tube that THERMAL-HYDRAULIC assumes. The presence of the hourglass inserts adds additional power to the fluid that THERMAL-HYDRAULIC cannot account for internally. To account for the additional power from the hourglasses, for the purpose of calculating bulk fluid temperature and film coefficient, the flux applied to the tubes was increased. Where the tube was flanked by two 30-mil hourglasses the flux was increased by $4 \%$, and where the tube was flanked by one 90-mil and one 30-mil hourglass the flux was increased by $8 \%$. This lumping method assumes that the losses from the hourglass are equivalent to losses from the tubes. The addition of the power from the hourglass as modified to. run in THERMAL-HYDRAULIC is shown schematically in Figure 5 .

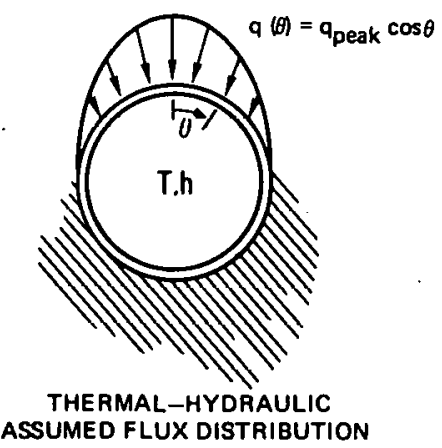

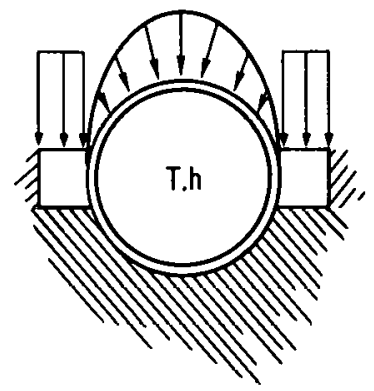

ACTUAL DISTRIBUTION ON HOURGLASS/TUBE COMBINATION

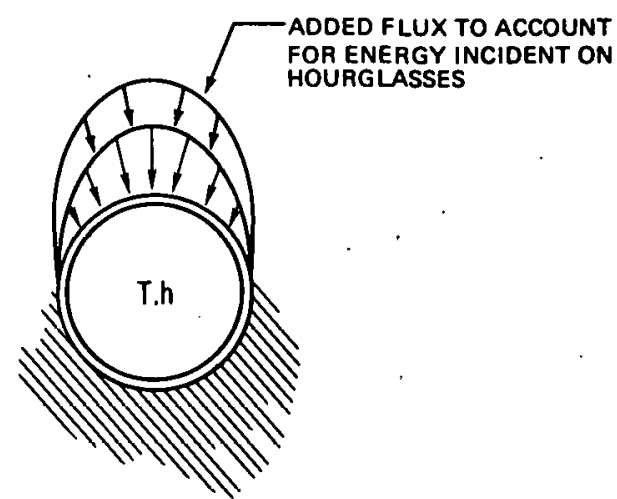

MODIFIED FLUX DISTRIBUTION USED IN THERMAL HYDRAULIC FOR CALCULATION OF INTERNAL FILM COEFFICIENT AND BULK FLUID TEMPERATURE

Figure 5. Modification to THERMAL-HYDRAULIC Model to Account for Hourglasses

To account for the lateral flux distribution, several panel tubes (the center tube, an edge tube, and several in between) were analyzed using THERMALHYORAULIC while the gross mass flow rate was adjusted so that with an input manifold temperature of $316^{\circ} \mathrm{C}\left(600^{\circ} \mathrm{F}\right)$ the output manifold temperature of the combined fluid from all the tubes was $593^{\circ} \mathrm{C}\left(1100^{\circ} \mathrm{F}\right)$, the desired goal. Because of this adjustment the exit fluid temperature from the center tube (the tube receiving the most complete analysis) was higher than $593^{\circ} \mathrm{C}\left(1100^{\circ} \mathrm{F}\right)$. These adjustments were made for both high and low flux. 


\section{Linear Crown Strain Analysis}

The results of the THERMAL-HYDRAULIC analyses were used as input to the SNLL in-house computer program TUBEBND,' which generates a linear strain model of a thermally loaded beam (the tube) over user-defined supports. These supports can be simple knife edges, fixed supports, or simple rotational springs. The knife-edge and fixed-support cases were used to bound the problem since the actual support stiffness falls between these two extremes.

The output of TUBEBND is the crown strain along the tube (see Figure 6). As can be seen in Figure 6 , there is a relatively long section over which the crown strain is at or near its maximum value. To choose the worst section for further finite element analysis, crown strain and crown temperature (as computed by THERMAL-HYDRAULIC) were compared to find the section where both were closest to their maximum. The position of the nearest THERMAL-HYDRAULIC node was used as the section for the finite element analysis, with THERMALHYDRAULIC's values for absorbed flux, bulk fluid temperature, film coefficient, and fluid pressure used for the finite element calculations. The worst locations were judged to be $2.52 \mathrm{~m}(8.28 \mathrm{ft})$ up the panel for the high flux and $2.68 \mathrm{~m}(8.79 \mathrm{ft})$ up the panel for the low flux.

TUBE AXIS (M)

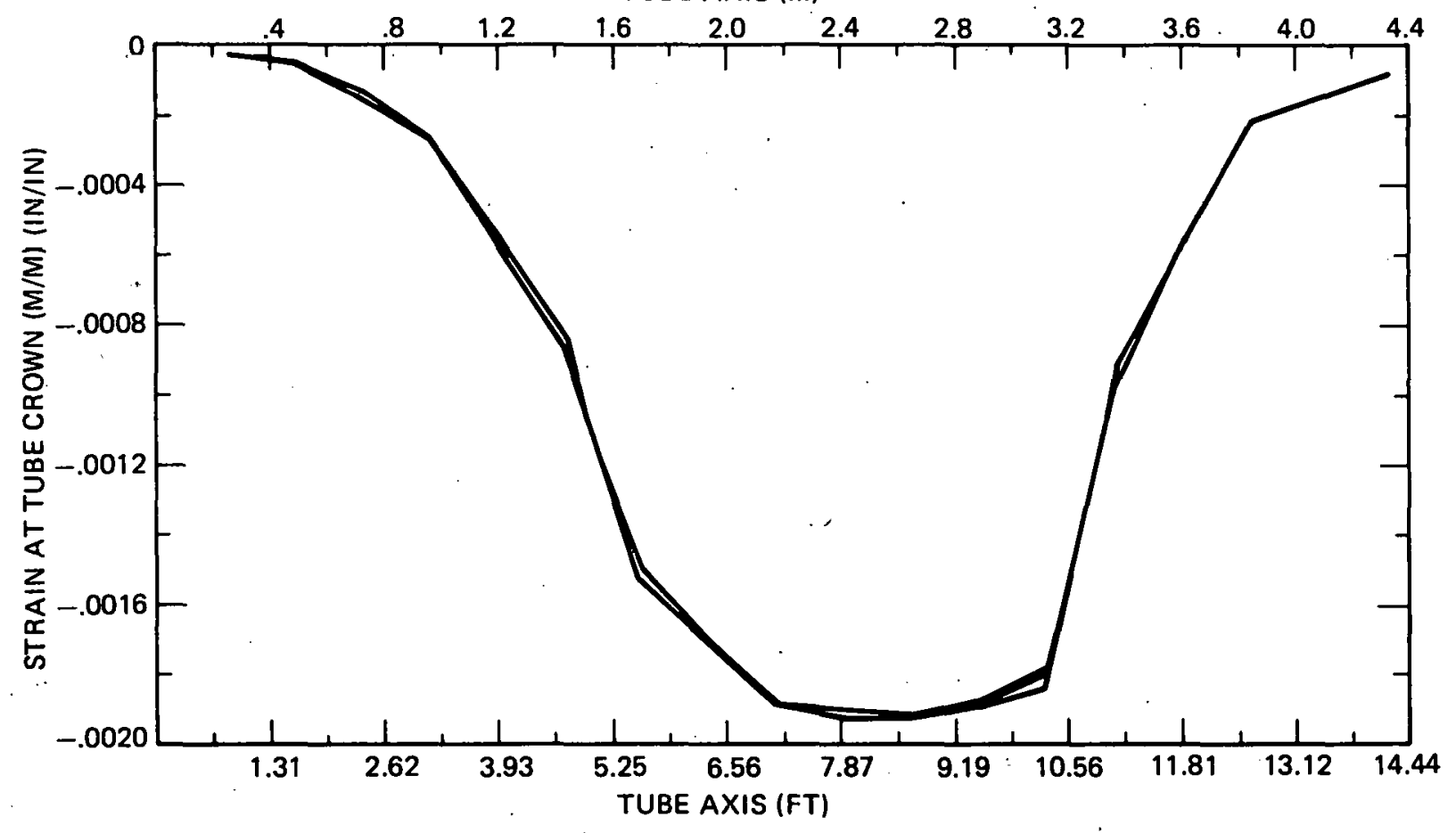

Figure 6. TUBEBND Sample Analysis Output. The two curves represent knife-edge and fixed-support cases. 
Thermal Finite Element Analysis

After the thermal-hydraulic and linear crown strain analyses had isolated the worst sections for the low- and high-flux cases, numerous finite element analyses were conducted to represent the different geometries and investigate the effect of various parameters and assumptions. Five different geometries were studied in both the thermal and structural finite element analyses: tubes with no insert, tubes with a 90-mil full hourglass insert, tubes with a 30-mil full hourglass insert, tubes with a 90-mil half-hourglass insert, and tubes with a 30-mil half-hourglass insert. The thermal finite element analyses examined both low and high incoming fluxes. Since these were assumed to be planar incoming fluxes, a diffuse incoming high flux was also examined to understand the sensitivity of the analyses to the assumption of a planar flux angular distribution. For the cases of tubes only and tubes with half hourglasses, the effect of reradiation between tube and hourglass front surfaces was studied.

Two different finite element computer codes were used for the thermal analyses, MARC ${ }^{2}$ and TACO. 3 MARC is a commercially available general purpose. finite element program which can perform both linear and nonlinear analyses involving temperature-dependent properties in either steady state or transient time domains. For the thermal analyses an eight-node planar biquadratic quadrilateral conduction-heat-transfer-only element was used. A sample mesh for the 30-mil full hourglass is shown in Figure 7. TACO is an SNLL in-house two-dimensional implicit finite element code for heat transfer analysis, which can also perform both linear and nonlinear analyses involving temperaturedependent properties in either steady state or transient time domains. TACO uses a four-node quadrilateral element for the coupled heat conduction and enclosure radiation calculations. The meshes used for the TACO analyses were similar to those used for the MARC analyses.

The boundary conditions for the thermal finite element models were obtained from the thermal hydraulic analysis. The exterior flux applied on the front surface was taken as a cosine distribution on the exposed tube and unit value on the exposed face of the hourglass multiplied by the net value of absorbed flux on the tube crown. The value of the net absorbed flux at the axial location of interest was taken from THERMAL-HYDRAULIC. The bulk fluid temperature and fluid film coefficient were obtained from the $104 \%$ and $108 \%$ flux cases for the 30- and 90-mil hourglasses, respectively, and from the standard $(100 \%)$ flux case for the tube only. The only material property necessary was the value for the thermal conductivity, which was assumed to be linear between $11.35 \mathrm{~W} / \mathrm{m}{ }^{\circ} \mathrm{C}$ at $-18^{\circ} \mathrm{C}\left(6.56 \mathrm{Btu} / \mathrm{h} \mathrm{ft}{ }^{\circ} \mathrm{F}\right.$ at $\left.0^{\circ} \mathrm{F}\right)$ and $23.89 \mathrm{~W} / \mathrm{m}{ }^{\circ} \mathrm{C}$ at $760^{\circ} \mathrm{C}\left(13.80 \mathrm{Btu} / \mathrm{h} \mathrm{ft}{ }^{\circ} \mathrm{F}\right.$ at $\left.1400^{\circ} \mathrm{F}\right)$. The braze was assumed to have identical thermal properties as the Incoloy tube and hourglass. Table II summarizes the important boundary conditions for the MARC thermal finite element analyses with planar incoming flux. 


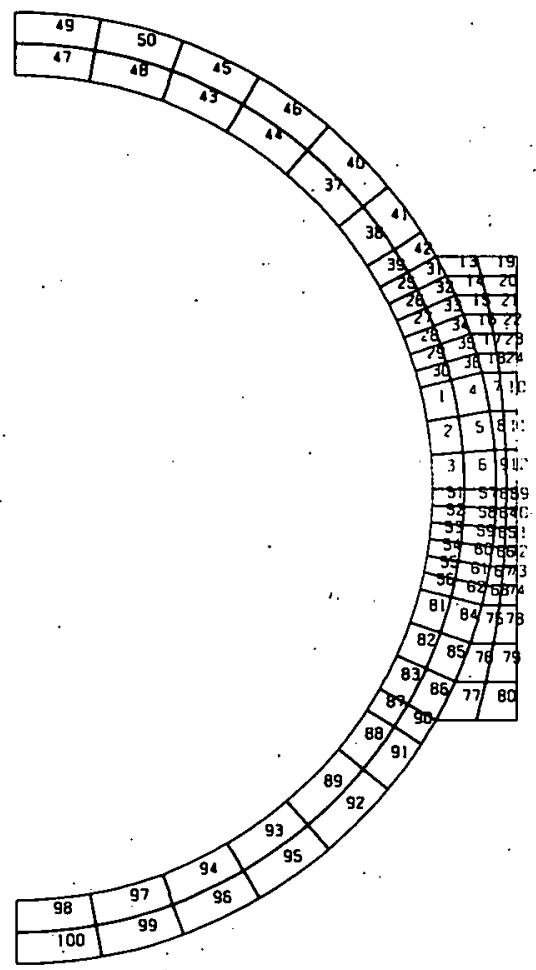

Figure. 7. Finite-Element Mesh for 30-mil Full Hourglass MARC Thermal Analyses

TABLE II

MARC - THERMAL FINITE ELEMENT ANALYSIS INPUTS

Applied planar flux peak* (net) (high flux)

Applied planar flux peak (net) (low flux)

Interior film coefficient (high flux)

Interior film coefficient (low flux)

Bulk fluid temperature (high flux)

Bulk fluid temperature (low flux)

Tube wall conductivity (linear)
$1.44 \mathrm{MW} / \mathrm{m}^{2}\left(456,000 \mathrm{Btu} / \mathrm{h} \mathrm{ft}^{2}\right)$

$0.61 \mathrm{MW} / \mathrm{m}^{2}\left(195,000 \mathrm{Btu} / \mathrm{h} \mathrm{ft}^{2}\right)$

$27403 \mathrm{~W} / \mathrm{m}^{2} \mathrm{~K}\left(4833 \mathrm{Btu} / \mathrm{h} \mathrm{ft}{ }^{2}{ }^{\circ} \mathrm{F}\right)$

$26422 \mathrm{~W} / \mathrm{m}^{2} \mathrm{~K}\left(4660 \mathrm{Btu} / \mathrm{h} \mathrm{ft}^{2}{ }^{\circ} \mathrm{F}\right)$

$483^{\circ} \mathrm{C}\left(901^{\circ} \mathrm{F}\right)$

$518^{\circ} \mathrm{C}\left(964^{\circ} \mathrm{F}\right)$

$11.35 \mathrm{~W} / \mathrm{m} \mathrm{K} \odot-18^{\circ} \mathrm{C}$ to $23.89 \mathrm{~W} / \mathrm{m} \mathrm{K}$ e $760^{\circ} \mathrm{C}\left(6.56 \mathrm{Btu} / \mathrm{h} \mathrm{ft}{ }^{\circ} \mathrm{F}\right.$ @ $0^{\circ} \mathrm{F}$ to $13.80 \mathrm{Btu} / \mathrm{h} \mathrm{ft}{ }^{\circ} \mathrm{F}$ (o $1400^{\circ} \mathrm{F}$ )

*Except for diffuse flux case where diffuse flux absorbed was set equal to planar flux absorbed over whole tube-hourglass surface. 
For analysis of the case where the incoming flux was assumed to be diffuse, it was necessary to do two finite element analyses. First, a TACO model accepting radiation input from an infinite plane was used to calculate the distribution of flux over the surface of the tube and hourglass. The distribution was normalized such that the power incident on one tube and one hourglass was the. same as for the planar incoming flux cases after losses.

Once the net incoming flux distribution over the surface had been established, (for both the diffuse and planar cases), it was applied to the appropriate MARC thermal finite element model. The MARC model was chosen over TACO for the steady state conduction solution because it uses a higher order (8-node vs 4-node) element, which is compatible with the subsequent structural finite element calculations. The output of the MARC thermal analyses was stored on tape for later use in the structural analyses. A sample graphical representation of the output showing isotherms for the 30-mil full hourglass case is shown in Figure 8 .

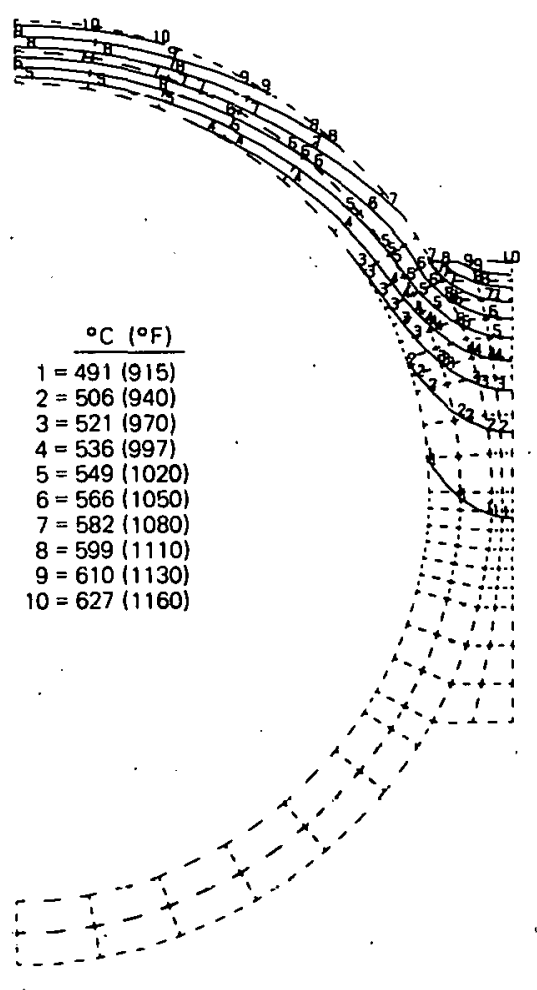

Figure 8. Temperature Profiles for 30-mil Full Hourglass under High Flux

Concern arose over ignoring possible cavity reradiation effects in the effective cavity between tubes in the tube-only and half-hourglass cases. This effective cavity is shown by the shaded area in Figure 9. To allay this concern the enclosure radiation capabilities of TACO were used to ascertain 
the amount of redistribution of energy by cavity reradiation. Both planar and diffuse incoming flux were examined. Table III summarizes the inputs used for the cavity reradiation analysis of the three cases: no hourglass, 30-mil half hourglass, and 90-mil half hourglass. The surface temperatures on the tube vary little (less than $3^{\circ} \mathrm{C}$ between the analyses with and without reradiation so it was concluded that reradiation inside the cavity generates no significant effect and can be safely ignored.

INCOMING SOLAR FLUX
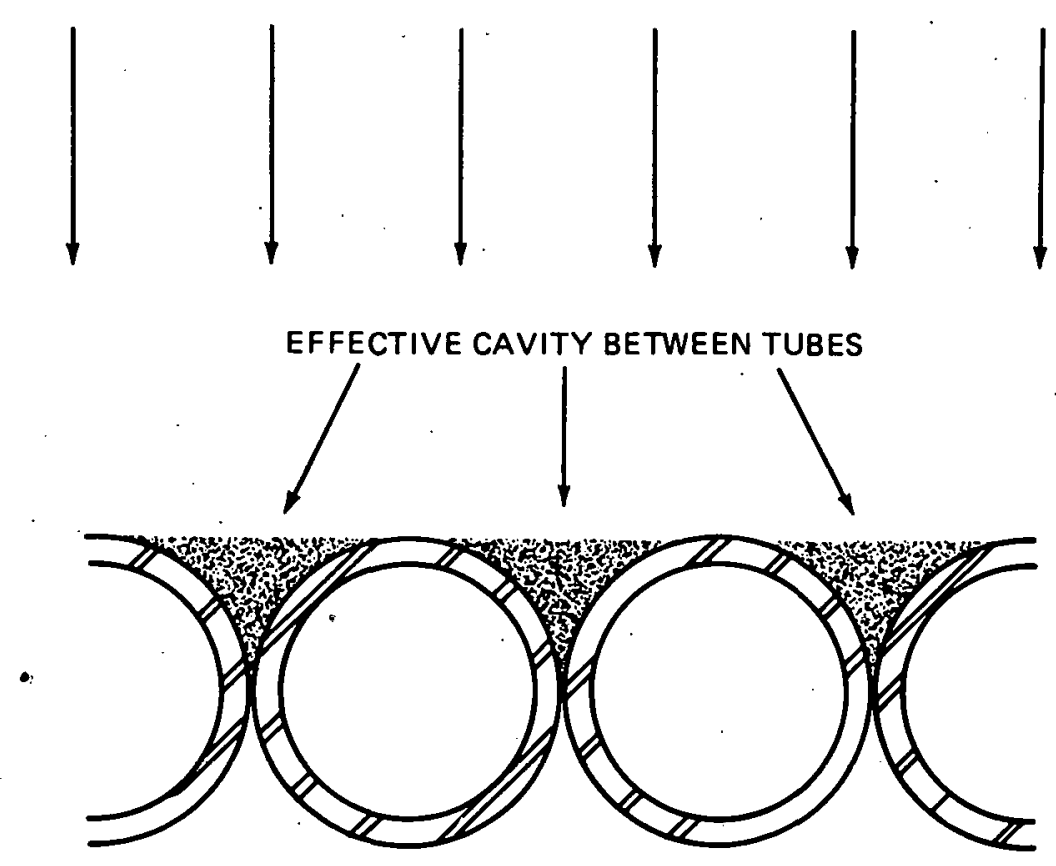

Figure 9. Effective Cavity between Tubes

\section{Structural Finite Element Analysis}

Once the thermal finite element analyses had established the thermal profiles of the sections in question, detailed structural finite element analyses were done. Table IV displays the geometric and flux cases analyzed structurally. In addition to these, analyses were run (a) with altered material properties and (b) assuming the existence of a crack or flaw in the braze. 
TABLE II I

TACO THERMAL FINITE ELEMENT ANALYSIS INPUTS

\begin{tabular}{|c|c|}
\hline Ambient temperature & $21^{\circ} \mathrm{C}\left(70^{\circ} \mathrm{F}\right)$ \\
\hline Interior film coefficient & $27,403 \mathrm{~W} / \mathrm{m}^{2} \mathrm{~K}\left(4833 \mathrm{Btu} / \mathrm{h} \mathrm{ft}^{2}{ }^{\circ} \mathrm{F}\right)$ \\
\hline $\begin{array}{l}\text { Bulk fluid temperature } \\
\text { (high flux case) }\end{array}$ & $483^{\circ} \mathrm{C}\left(901^{\circ} \mathrm{F}\right)$ \\
\hline Exterior film coefficient & $9.53 \mathrm{~W} / \mathrm{m}^{2} \mathrm{~K}\left(1.68 \mathrm{Btu} / \mathrm{h} \mathrm{ft}^{2}{ }^{\circ} \mathrm{F}\right)$ \\
\hline Emissivity $\varepsilon$ & 0.95 \\
\hline Absorbtivity a & 0.95 \\
\hline $\begin{array}{l}\text { Tube wall conductivity } \\
\text { (linear) }\end{array}$ & $\begin{array}{l}11.35 \mathrm{~W} / \mathrm{m} \mathrm{K} \text { ( }-18^{\circ} \mathrm{C} \text { to } 23.89 \mathrm{~W} / \mathrm{m} \mathrm{K} \\
0760^{\circ} \mathrm{C}\left(6.56 \mathrm{Btu} / \mathrm{h} \text { ft }{ }^{\circ} \mathrm{F} \mathrm{O} 0^{\circ} \mathrm{F} \text { to }\right. \\
\left.13.80 \mathrm{Btu} / \mathrm{h} \mathrm{ft}{ }^{\circ} \mathrm{F} \text { o } 1400^{\circ} \mathrm{F}\right)\end{array}$ \\
\hline
\end{tabular}

TABLE IV

GEOMETRIC AND FLUX CASES ANALYZED

High Flux $\left(1.5 \mathrm{MW} / \mathrm{m}^{2}\right)$

$\left(475,600 \mathrm{Btu} / \mathrm{h} \mathrm{ft}^{2}\right)$

Low Flux $\left(0.64 \mathrm{MW} / \mathrm{m}^{2}\right)$

$\left(202,900 \mathrm{Btu} / \mathrm{h} \mathrm{ft}^{2}\right)$

Tube with 90-mil full hourglass

Tube with 90-mil full hourglass

Tube with 30-mil full hourglass

Tube with 30-mil full hourglass

Tube with 30-mil full hourglass

Tube only

with diffuse incoming flux

Tube with 90-mil half hourglass

Tube with 30-mil half hourglass

Tube only 
The MARC finite element code was used for all structural analyses. It can perform both linear and nonlinear analyses involving temperature-dependent material properties. A ten-node generalized plane strain element was used: In addition to the eight nodes for the conventional biquadratic representation of plane strain (in $x-y$ coordinates), two additional bulk nodes (common to all the elements) express gross (or average) $z$ strain and $z-x$ and $y-z$ rotations. A sample mesh for the 30-mil full hourglass case is shown in Figure 10. For the crack analysis, a gap-link element was interposed to allow sliding between the hourglass and the tube across the crack.

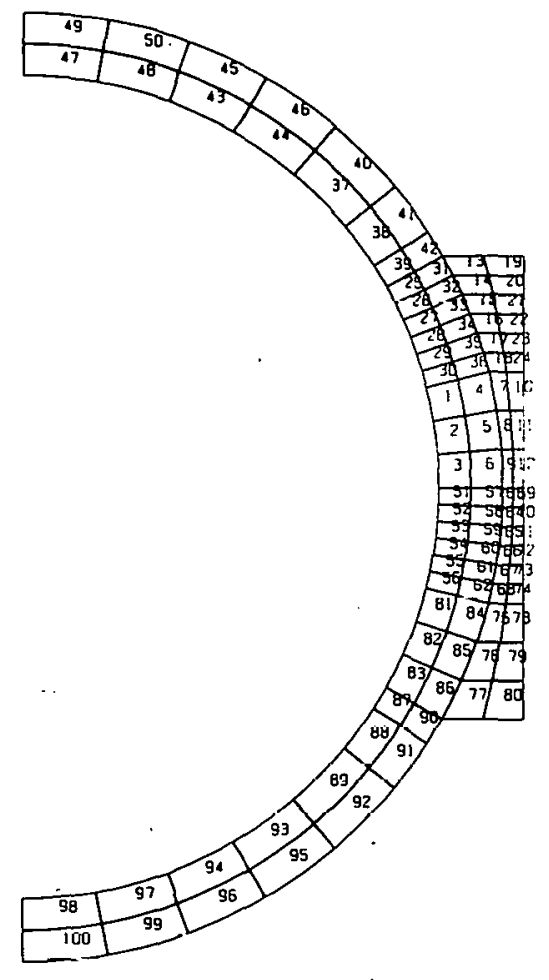

Figure 10. Finite-Element Mesh for 30-mil Full Hourglass MARC Stress Analysis

The boundary conditions for the structural analyses fall into two sets, thermal and geometric. The temperature distribution across the section was input via tape from the thermal finite element analysis. The geometric boundary conditions were based on the requirement that the panel in service remain flat. Because of attachments between the panel and the supporting structure, no axial or lateral flexing of the panel was permitted. This resulted in placing symmetry planes through the center of the hourglass and the center of the tube (as shown in Figure 11), which were tied in such a way as 
to permit lateral growth but prevent differential rotation. Gross axial growth (due to thermal strains) was allowed.

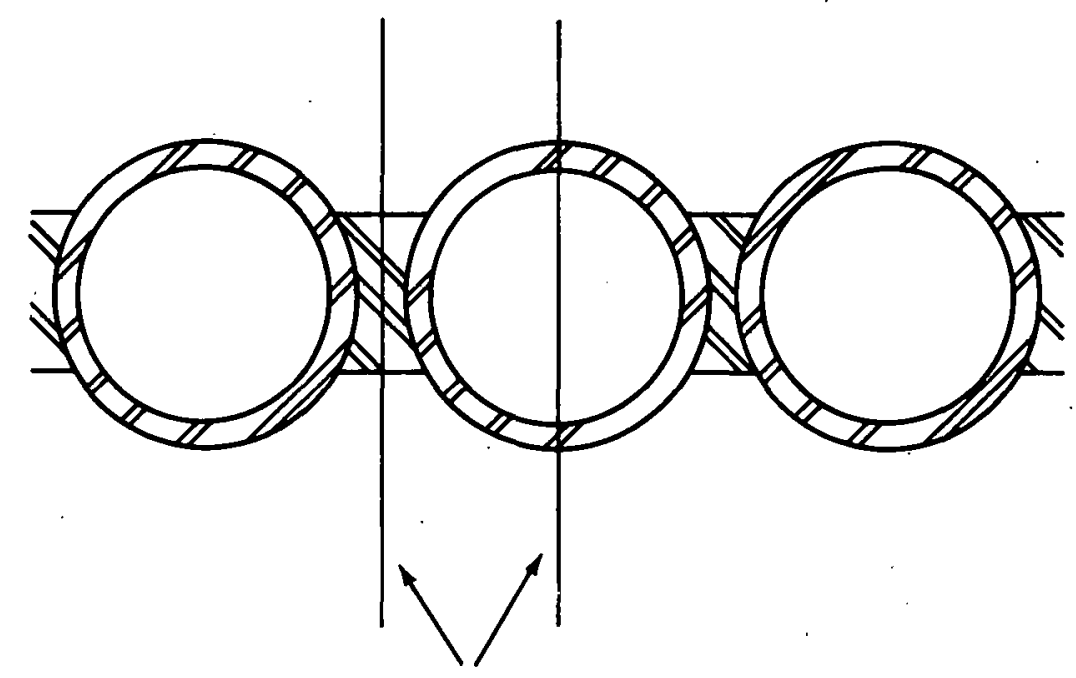

ASSUMED SYMMETRY LINES

Figure 11. Location of Assumed Symmetry Lines

The ability of MARC to implement analyses with temperature-dependent material properties was used extensively. The temperature dependence of the coefficient of thermal expansion $(\alpha)$, Poisson's ratio $(v)$, the Von Mises yield stress, and the elastic modulus (E) are displayed in Figure 12. The stressstrain behavior was modelled as bilinear with fixed work-hardening slope, but with a temperature-dependent yield point and elastic modulus. The resultant behavior is shown schematically in Figure 13. A conservatively* high value of $3 \times 10^{4} \mathrm{MPa}\left(4.35 \times 10^{6} \mathrm{psi}\right)$ for the work-hardening slope was chosen initially for all analyses, but the influence of this number was checked parametrically to observe it.s effect on predicted lifetime (the parametrization involved an analysis using a fixed work-hardening slope of $3.45 \times 10^{3} \mathrm{MPa}$. The choice of $3 \times 10^{4} \mathrm{MPa}$ for the work-hardening slope is consistent, based on strain range and temperature, with the experimental data presented by Maiya. ${ }^{4}$

*In the sense of ASME lifetime, the smaller the strain range the longer the life; higher work hardening slopes produce smaller strain ranges in this problem. 

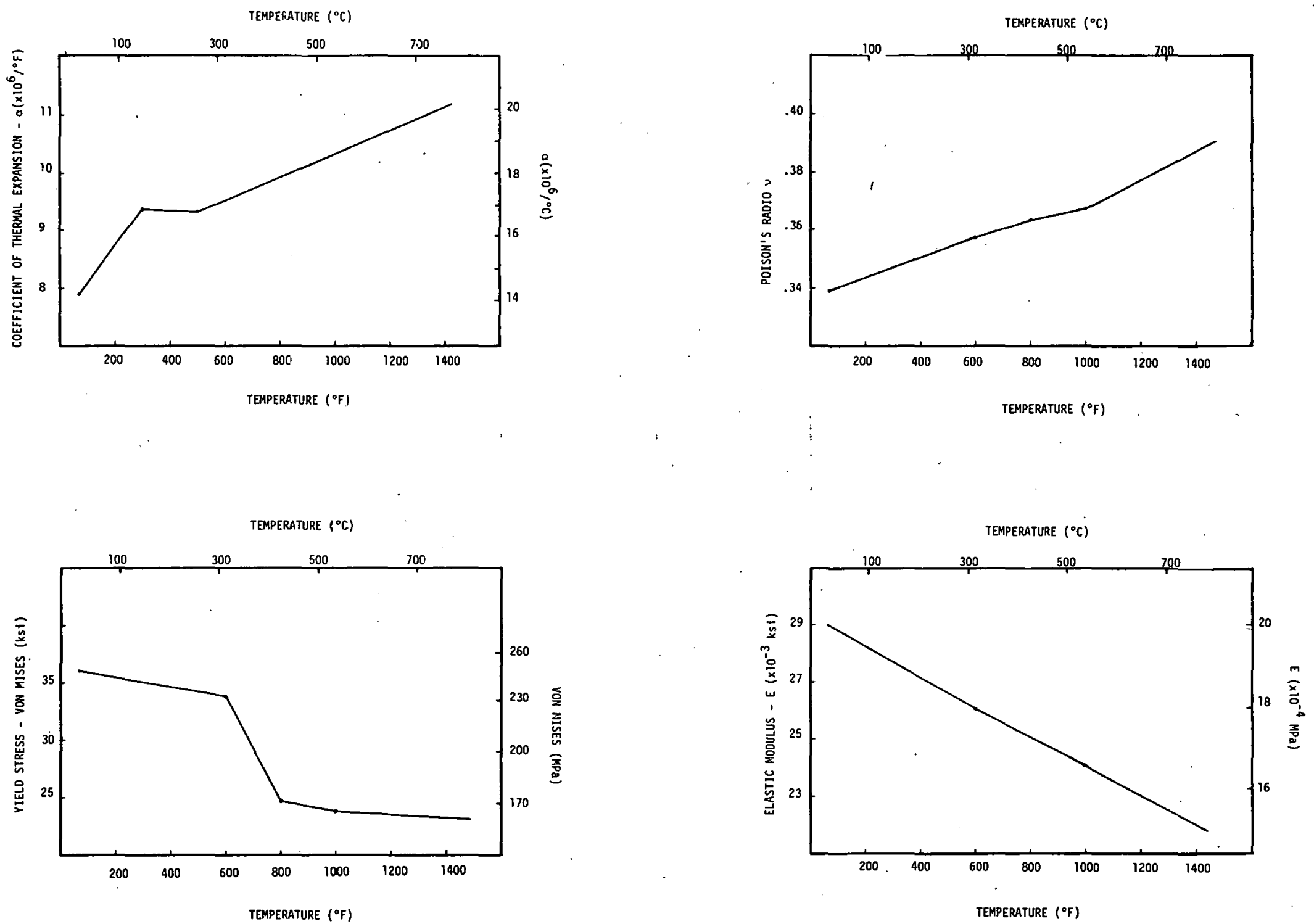

Figure 12. Material Properties for Stress Analysis 


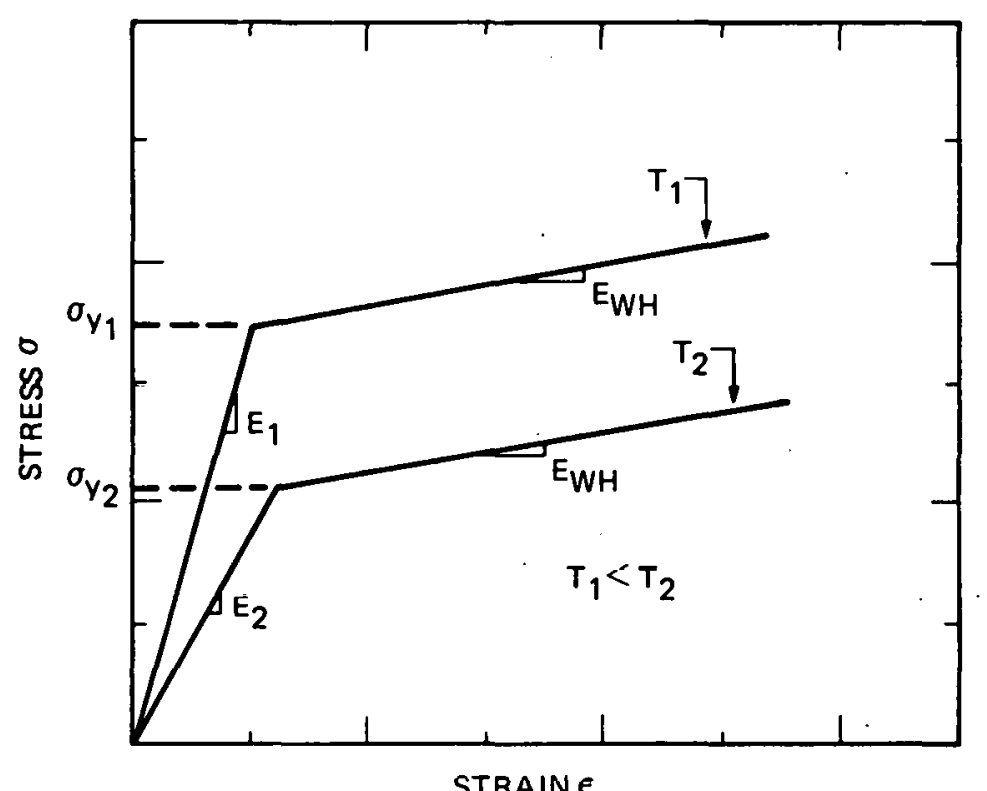

Figure 13. Model of Material Stress-Strain Behavior

For the actual analysis, the equilibrium temperature of the tube and hourglass was specified to be several degrees cooler than the bulk fluid temperature. The temperature profile (stored on tape) was then applied in steps, each step representing a proportional increase in temperature with proportionality measured against the difference between the equilibrium temperature and the temperature at power. At each step, the model was allowed to come to structural equilibrium based on a defined energy tolerance. This method of application of the thermal gradient models the first cycle power up of the receiver panel. Since no creep or cyclic material hardening effects are included, the analyses cannot represent the shakedown of the panel to a stable strain cycle. However, previous analyses have shown that the strain range experienced in a first cycle power-up analysis is 1 ess than $10 \%$ greater than the strain range in a full cycle after shakedown, so the results of the analysis were considered reasonably accurate.

The crack analysis was run on the 90-mil full hourglass high-flux case since this case had the largst calculated stresses in the braze. Some minor changes in the finite element model were necessary to allow the penetration of the crack. Gap-link elements were interposed between elements along the braze (see Figure 14). The ends of these members were tied together and released sequentially from the front of the braze towards the rear, thereby generating a sliding interface (the crack) which at the end of the analysis had released $25 \%$ of the braze. At each step as a gap-link element was released, the stressstrain state of the model was allowed to re-equilibrate. While this mudel could not incorporate all the facets of a crack progression through the braze, it is felt that its sequential nature allows an understanding of a crack's effect on the stress-strain fields of the hourglass-tube assembly. 


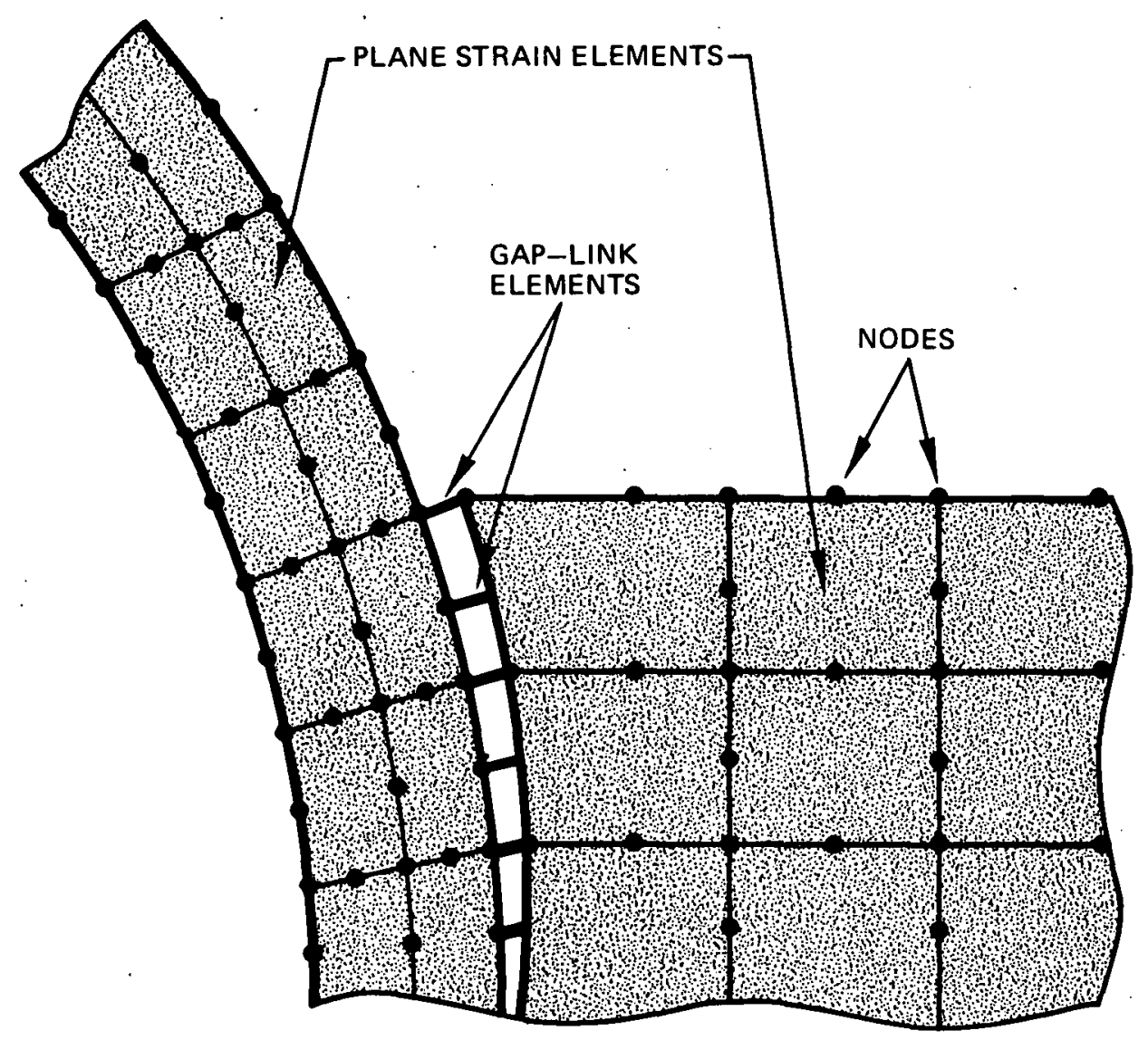

Figure 14. Placement of Gap Link Elements

\section{Stress-Strain Results}

The MARC code generates the stresses $\sigma_{x}, \sigma_{y}, \sigma_{z}$, and $\tau_{x y}$, and the strains $\varepsilon_{x}, \varepsilon_{y}, \varepsilon_{z}$, and $\gamma_{x y}$, both total and plastic, at each intra-element integration point. In addition the code outputs the principal stresses and strains as well as several stress intensities (e.g., the Tresca stress intensity). The values for $x x$ stress, yy stress, $z z$ stress, $z z$ plastic strain, $x y$ stress, $x y$ plastic strain, equivalent stress, and equivalent plastic strain were graphically plotted for the ten cases studied (see Appendix A for examples). The stresses and strains around the crack in the crack simulation model were analyzed separately and are discussed below.

There were several areas of concern common to all the cases studied and particular attention was paid to them. They are (1) the tube crown, (2) the hourglass crown, (3) the tube wall just forward of the braze, and (4) the braze front and back corners. An examination of the plots in Appendix $A$ shows that these are areas of stress-strain concentration. For these locations, an equivalent strain was calculated from the formula

$$
\varepsilon_{\mathrm{eq}}=(\sqrt{2} / 3)\left[\left(\varepsilon_{\mathrm{I}}-\varepsilon_{\mathrm{II}}\right)^{2}+\left(\varepsilon_{\mathrm{II}}-\varepsilon_{\mathrm{III}}\right)^{2}+\left(\varepsilon_{\mathrm{III}}-\varepsilon_{\mathrm{I}}\right)^{2}\right]^{1 / 2}
$$


where $\varepsilon_{I, I I, I I I}$ are the principal strains. For the tube crown, hourglass crown, and tube wall just forward of the braze, Table $V$ presents the calculated equivalent strains for the high flux conditions.

TABLE V

EQUIVALENT STRAINS $[\mathrm{m} / \mathrm{m}$ (in./in.) ]

\begin{tabular}{|c|c|c|c|}
\hline & $\begin{array}{l}\text { Tube } \\
\text { Crown }\end{array}$ & $\begin{array}{c}\text { Hourglass } \\
\text { Crown }\end{array}$ & $\begin{array}{l}\text { Tube Just For- } \\
\text { ward of Braze } \\
\end{array}$ \\
\hline Tube only & .002566 & - & - \\
\hline 90-mil full hourglass & .002008 & .002288 & .002929 \\
\hline 30-mil full hourglass & .002119 & .002011 & .002330 \\
\hline $\begin{array}{l}30-m i l \text { full/diffuse } \\
\text { flux }\end{array}$ & .002149 & .001623 & .002244 \\
\hline $\begin{array}{l}\text { 30-mil full/lower work } \\
\text { hardening }\end{array}$ & .002161 & .002047 & .002641 \\
\hline 90-mil half hourglass & .002092 & .001275 & .000843 \\
\hline 30-mil half hourglass & .002220 & .000350 & .000639 \\
\hline
\end{tabular}

For the calculation of stresses at the front corner and back corner of the braze it was necessary to transform the calculated $\sigma_{x}, \sigma_{y}$, and $\tau_{x y}$ stresses to coordinate directions parallel and transverse to the braze surface so that. a braze shear stress and transverse stress could be ascertained. The transverse and shear stresses at the integration points closesl lo the braze front corner and braze back corner are displayed in Table VI.

For the crack analysis, the calculated stresses were al so transformed to resolve them into components transverse and in plane with the braze, which was always assumed tangential to the tube wall. The analysis only generates stress values at discrete points, so a smooth curve was drawn through the plotted values. Figure 15 displays the transverse and shear stresses along the front quarter of the uncracked braze. As the crack progresses inward, the form of the shear stress curve stays the same, but the magnitude decreases. Figures 16-20 show the shear and transverse stresses on the braze for crack lengths of one element $(0.436 \mathrm{~mm})$ up to five elements $(2.10 \mathrm{~mm})$. Note that for the longer cracks there is an area of no transverse stress; this will be discussed in the next section. Figure 21 shows the shear stress distribution along the front quarter of the braze for a sequential opening of the crack. 
TABLE VI

BRAZE LOADS [MPa (ksi)]

\begin{tabular}{|c|c|c|c|c|}
\hline & \multicolumn{2}{|c|}{ Front Corner } & \multicolumn{2}{|c|}{ Back Corner } \\
\hline & Transverse & Shear & Transverse & Shear \\
\hline $90 \mathrm{mil}$ full & $-162.0(-23.5)$ & $107.6(15.6)$ & $71.7(10.4)$ & $64.1(9.3)$ \\
\hline $30 \mathrm{mil} \mathrm{full}$ & $-124.1(-18.0)$ & $93.1(13.5)$ & $54.5(7.9)$ & $49.0(7.1)$ \\
\hline $\begin{array}{l}30 \mathrm{mil} \text { fuli/diffuse } \\
\text { flux }\end{array}$ & $-130.3(-18.9)$ & $92.4(13.4)$ & $52.4(7.6)$ & $46.9(6.8)$ \\
\hline $\begin{array}{l}30 \mathrm{mil} \text { full/lower } \\
\text { work hardening }\end{array}$ & $-115.8(-16.8)$ & $80.0(11.6)$ & $51.7(7.5)$ & $46.2(6.7)$ \\
\hline $30 \mathrm{mil}$ half & $-130.3(-18.9)$ & $88.3(12.8)$ & NA & NA \\
\hline 90 milhalf & $-135.1(-19.6)$ & $91.0(13.2)$ & NA & NA \\
\hline \multicolumn{5}{|l|}{ Low Flux } \\
\hline 90 mil full & $-105.5(-15.3)$ & $85.5(12.4)$ & $44.1(6.4)$ & $40.0(5.8)$ \\
\hline $30 \mathrm{mil}$ full & $-75.2(-10.9)$ & $73.1(10.6)$ & $32.4(4.7)$ & $29.0(4.2)$ \\
\hline
\end{tabular}

Each curve represents an element's length extension of the crack along the braze and the number above each curve is the length of the crack (e.g., $5=$ crack length of five elements). A dotted line follows the peak shear stress as the crack opens. 


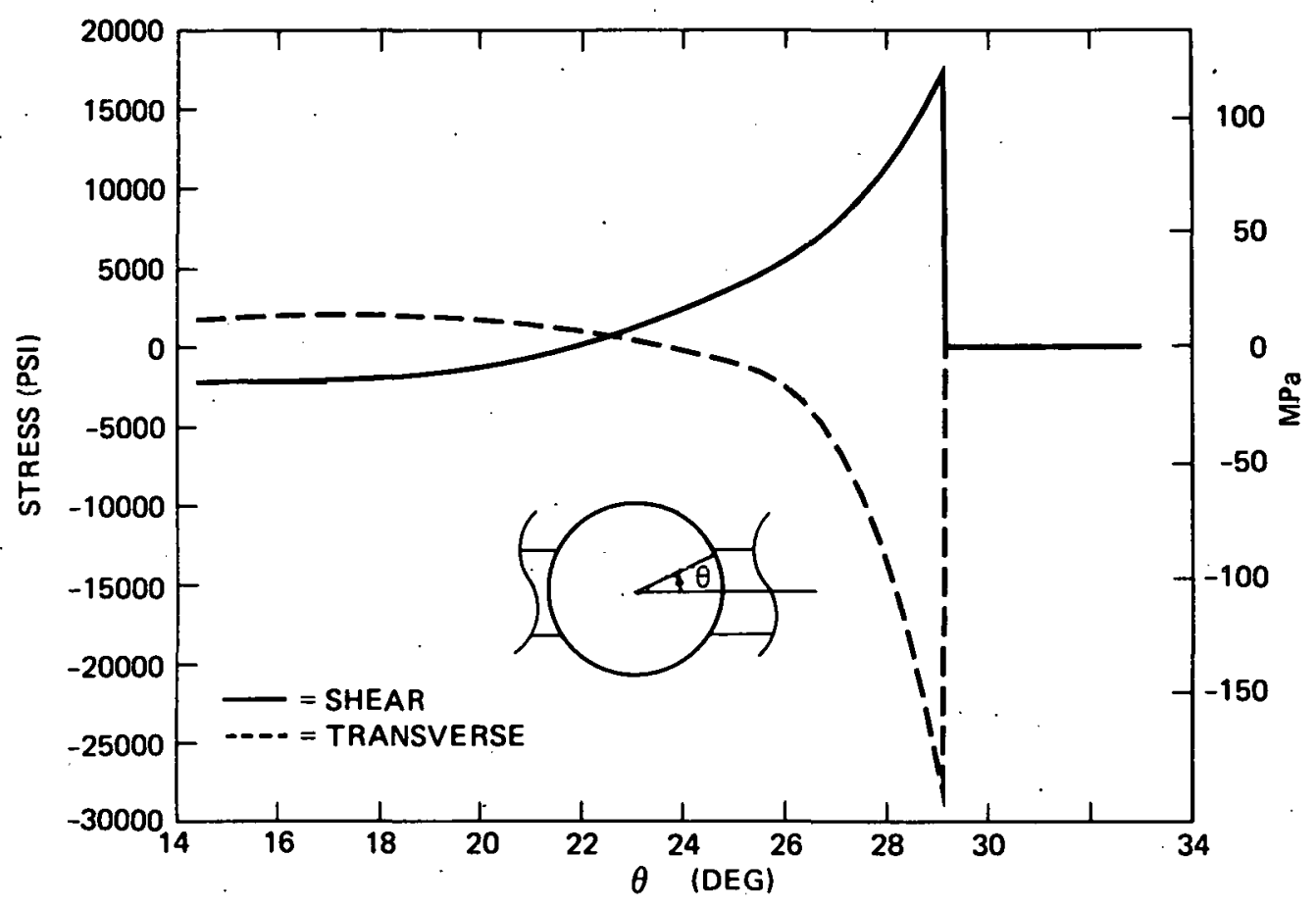

Figure 15. Transverse and Shear Stresses along Uncracked Braze (Front Quarter)

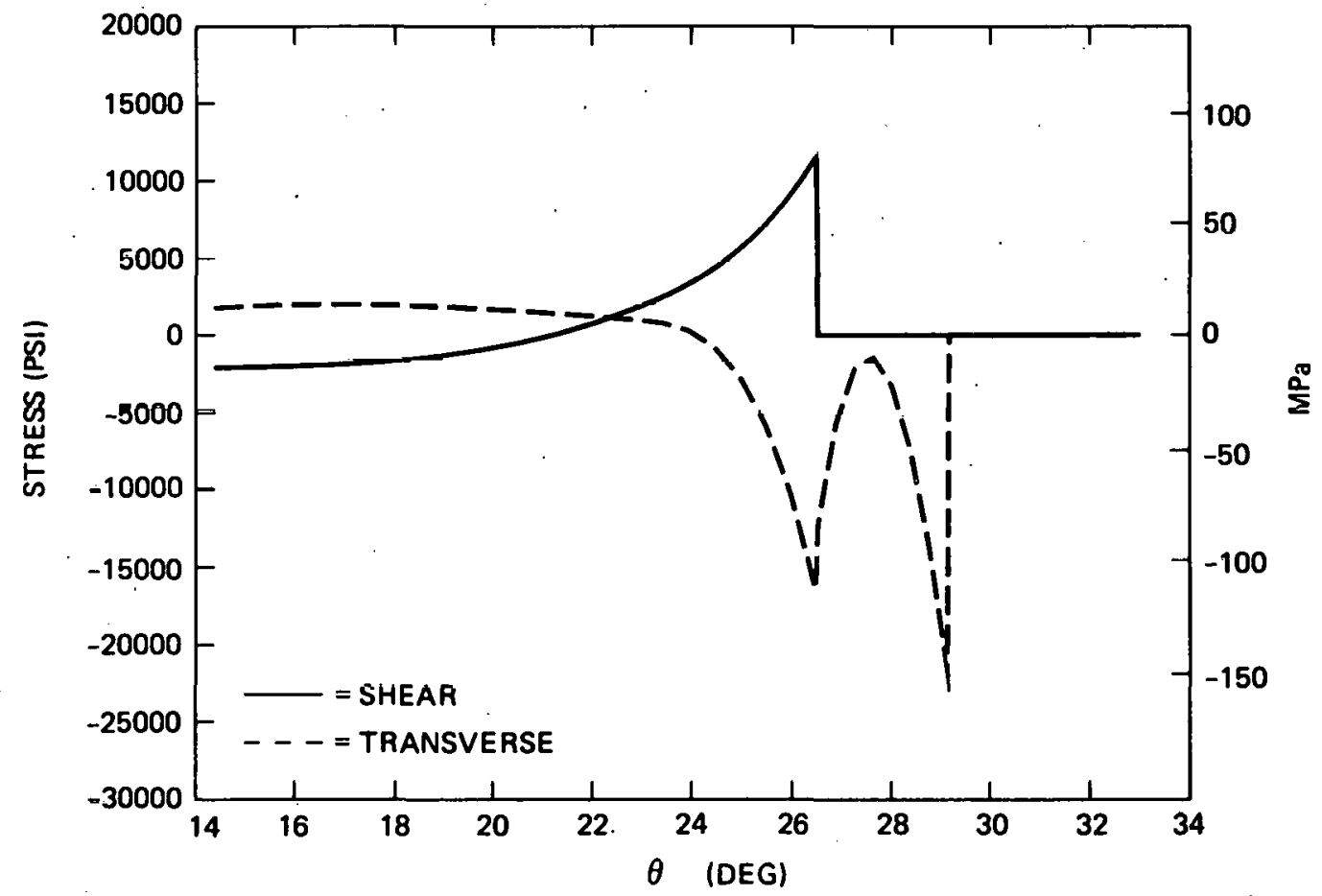

Figure 16. Transverse and Shear Stresses along One-Element Cracked Braze 


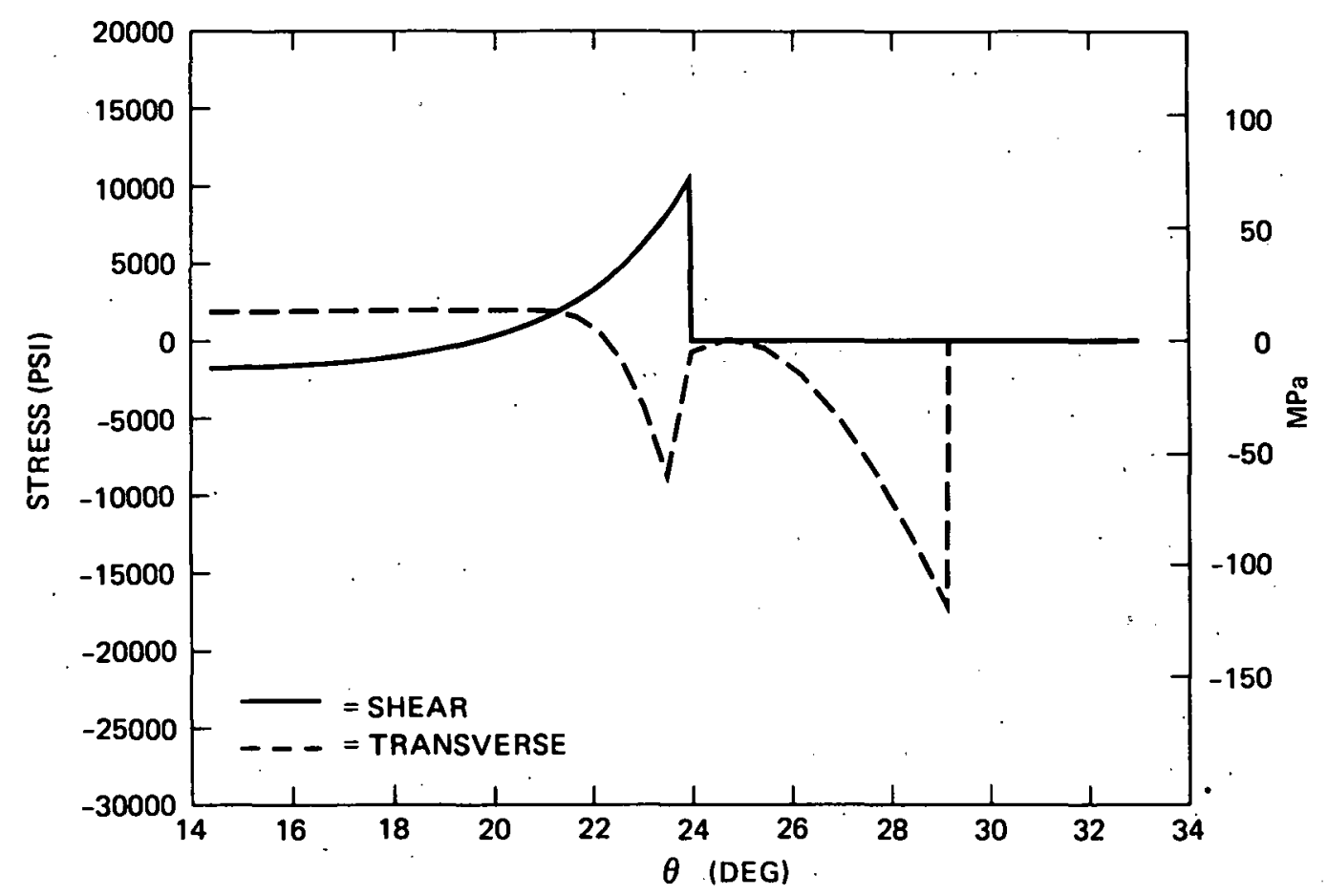

Figure 17. Transverse and Shear Stresses along Two-Element Cracked Braze

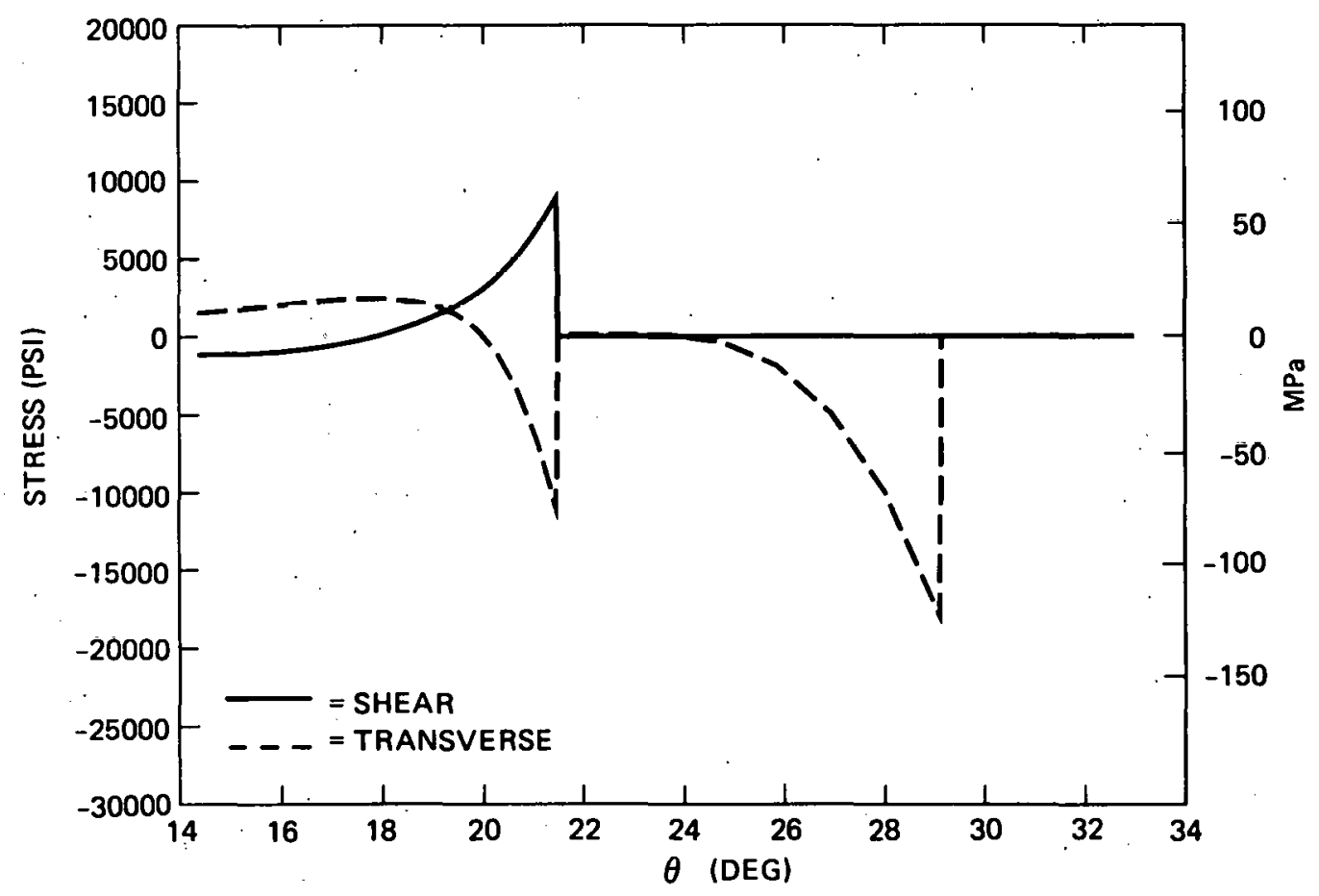

Figure 18. Transverse and Shear Stresses along Three-Element Cracked Braze 


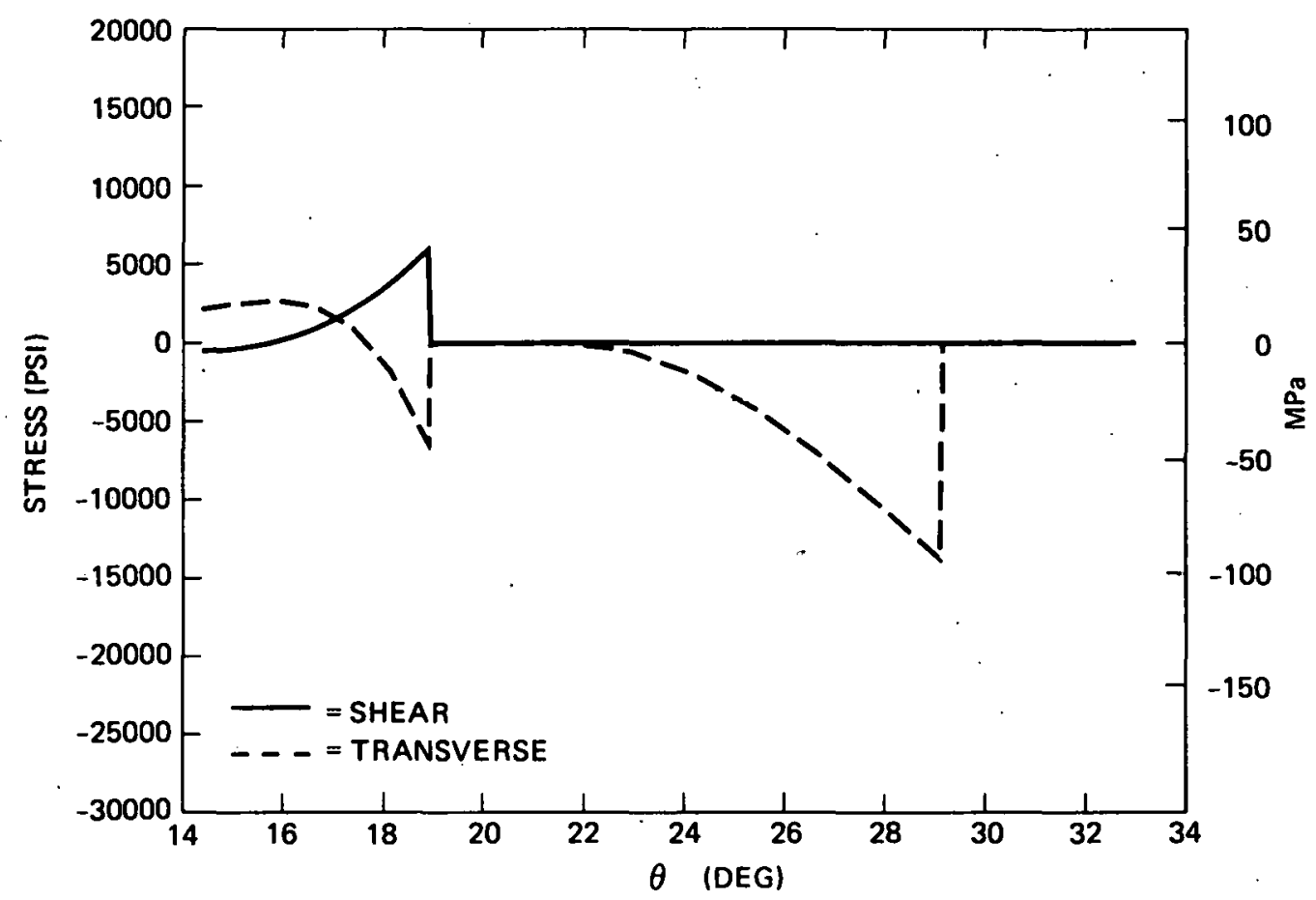

Figure 19. Transverse and Shear Stresses along Four-Element Cracked Braze

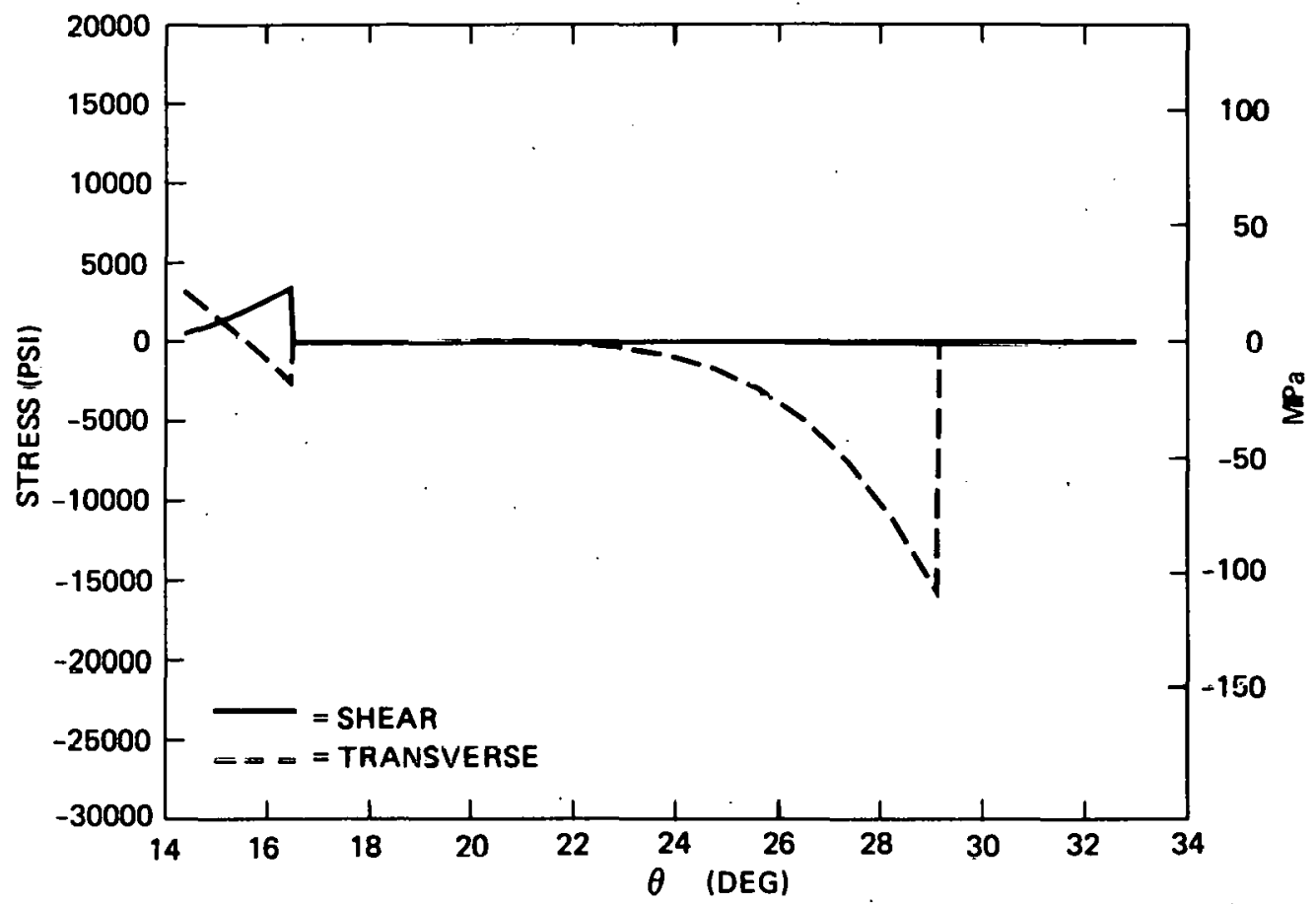

Figure 20. Transverse and Shear Stresses along Five-Element Cracked Braze 


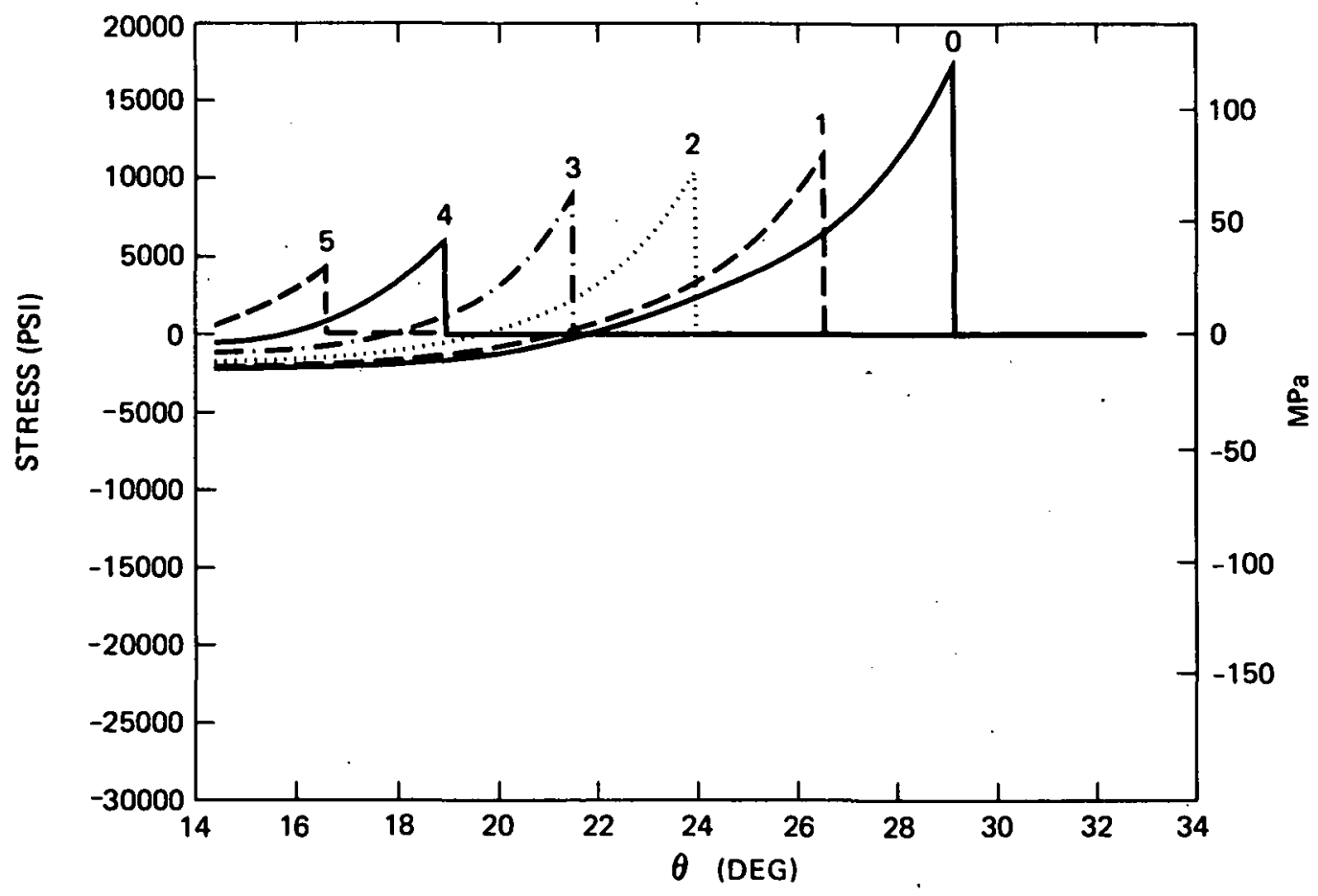

Figure 21. Evolution of Shear Stress along Braze during Sequential Crack Opening

Discussion

Once the MARC computer analyses were completed, several additional analytical steps were taken. (1) The equivalent strains at the areas of concern were used to calculate design lifetimes based on the "ASME Boiler and Pressure Vessel Code." 5 The calculations produce design lives (as opposed to mean lives) so that a high degree of confidence exists that the material in the area of interest will survive for that length of time. (2) An idealized structural model was generated to explain the behavior of the computer finiteelement models. (3) An error analysis was undertaken to enumerate sources of inaccuracy in the analyses.

\section{Fatigue-Life Calculations}

These calculations were conducted according to the "ASME Boiler and Pressure Vessel Code--Code Case N-47 (1592)," Section T-1414. The equivalent strain range was set equal to the maximum equivalent strain, calculated as discussed above, by assuming zero strain at the initial no-power-applied condition. The code case gives maximum equivalent strain range as a function of 1 ifetime and temperature for Incoloy $800 \mathrm{H}$, and these data were used for the Incoloy 800 in this analysis. For the calculation of lifetimes it was necessary to generate a surface fit to the data points tabulated in the code. A fourthorder, two-dimensional Chebycheff polynomial fit was used. The calculated polynomial coefficients were placed in a small computer program which would calculate lifetime (in cycles) based on equivalent strain range and temperature. 
The lifetimes for three critical areas (tube crown, hourglass crown, tube wall just forward of braze) at high flux as calculated by this program are given in Table VII along with the calculated temperatures.* The lifetimes for the low flux cases are not given as they are all greater than $10^{5}$ cycles. The effect of changing the material behavior (lowering the work hardening slope) had its most notable effect in the 1 ifetime calculations. As expected it lowered the peak stresses, but it al so increased the equivalent strain range and thus reduced the calculated design lifetime.

TABLE VII

ASME N-47 DESIGN LIFETIME (CYCLES)

\begin{tabular}{|c|c|c|c|}
\hline , & Tube Crown & $\begin{array}{c}\text { Hourglass } \\
\text { Crown } \\
\end{array}$ & $\begin{array}{l}\text { Tube Just For- } \\
\text { ward of Braze }\end{array}$ \\
\hline Tube only & $\begin{array}{c}2,370 \\
1196^{\circ} \mathrm{C}\left(647^{\circ} \mathrm{F}\right)\end{array}$ & -- & -- \\
\hline 90-mil full hourglass & $\begin{array}{c}7,450 \\
1166^{\circ} \mathrm{C}\left(630^{\circ} \mathrm{F}\right)\end{array}$ & $1195^{\circ} \mathrm{C}\left(646^{\circ} \mathrm{F}\right)$ & 2,620 \\
\hline 30-mil full hourglass & $\begin{array}{c}5,870 \\
1166^{\circ} \mathrm{C}\left(630^{\circ} \mathrm{F}\right)\end{array}$ & $\begin{array}{c}7,710 \\
1159^{\circ} \mathrm{C}\left(626^{\circ} \mathrm{F}\right)\end{array}$ & $\begin{array}{c}6,710 \\
1068^{\circ} \mathrm{C}\left(576^{\circ} \mathrm{F}\right)\end{array}$ \\
\hline $\begin{array}{l}30-m i l \text { full/diffuse } \\
\text { flux }\end{array}$ & $\begin{array}{c}5,520 \\
1166^{\circ} \mathrm{C}\left(630^{\circ} \mathrm{F}\right)\end{array}$ & $1121^{29} \mathrm{C}\left(605^{\circ} \mathrm{F}\right)$ & $\begin{array}{c}7,970 \\
1066^{\circ} \mathrm{C}\left(574^{\circ} \mathrm{F}\right)\end{array}$ \\
\hline $\begin{array}{l}\text { 30-mil full/lower work } \\
\text { hardening }\end{array}$ & $\begin{array}{c}5,390 \\
1166^{\circ} \mathrm{C}\left(630^{\circ} \mathrm{F}\right)\end{array}$ & $\begin{array}{c}7,710 \\
1159^{\circ} \mathrm{C}\left(626^{\circ} \mathrm{F}\right)\end{array}$ & $\begin{array}{c}4,050 \\
1068^{\circ} \mathrm{C}\left(576^{\circ} \mathrm{F}\right)\end{array}$ \\
\hline 90-mil half hourglass & $\begin{array}{c}6,200 \\
1166^{\circ} \mathrm{C}\left(630^{\circ} \mathrm{F}\right)\end{array}$ & $\begin{array}{c}169,000 \\
1098^{\circ} \mathrm{C}\left(592^{\circ} \mathrm{F}\right)\end{array}$ & $\frac{10^{5}}{977^{\circ} \mathrm{C}\left(525^{\circ} \mathrm{F}\right)}$ \\
\hline 30-mil half hourglass & $\begin{array}{c}4,820 \\
1166^{\circ} \mathrm{C}\left(630^{\circ} \mathrm{F}\right)\end{array}$ & $989^{10} \mathrm{C}\left(532^{\circ} \mathrm{F}\right)$ & $\frac{10^{5}}{956^{\circ} \mathrm{C}\left(513^{\circ} \mathrm{F}\right)}$ \\
\hline
\end{tabular}

Idealized Structural. Model.

This model was required to explain several phenomena observed in the stress analysis. The high $z$ direction tube (and hourglass) crown strain is due to the restraint by the supports, which restrict bending of the tube due to the thermal moment. The thermal gradient (from the front to the back of the tube) that produces this moment al so produces a compressive lateral crown

*The current design reference for the 30-year 1 ife of an SCR receiver panel is 50,000 cycles. 
strain in the tubes and hourglass when the latter are present because the panel behaves monolithically in the lateral direction and the panel supports prevent lateral bowing. Although the compressive lateral crown strain interacts with the vertical compressive crown strain to reduce the equivalent crown strain, and thus increase the crown life, the transfer of the thermal moment from the hourglass to the tube causes high bending moments and their resultant stresses and strains in the tube wall just forward of the hourglass braze.

The effect of any cont inuous intertube element (e.g., the hourglass or half hourglass) critically effects the tube crown strain. Placing the element towards the cool side of the panel increases the $z$ axis stiffness of the back side of the tubes and consequently increases the tube crown strain when the thermal gradient is applied.

The high braze shear stresses are due to the fact that the average hourglass temperature is higher than that of the tube wall to which it is attached. The temperature difference results in a thermal shear stress along the braze. Shear concentrations occur at the front and rear corners of the braze due to the geometric discontinuity. If a crack is induced at the front or back corner, the geometric discontinuity and hence the shear stress concentration follows the crack tip. For a crack starting at the front of the braze, the peak magnitude of the shear stress decreases as the crack progresses inward due to a decreasing ratio of released hourglass strain energy (which is highest at the front face of the hourglass) to crack length. The effect on stresses of a crack starting at the rear of the braze was not considered because the stresses are less threatening (the back of the braze is at a lower temperature).

\section{Error Analysis}

For these analyses, the errors fall into three broad categories: limits of the finite element analysis, modelling assumptions, and limits of the crack analysis. Higher accuracy could be achieved by using more elements or elements of higher numerical complexity. Geometric discontinuities (such as the corner between the hourglass and the tube) reduce the accuracy of the numerical approximations used. Extrapolating nodal values for stress and strain from the values of stress and strain at the internal integration points are also a possible source of error.

The difference between the idealized thermal/structural model and actual tube-hourglass assembly must be addressed. As was discussed earlier the actual as-built geometry uses a dogbone-shaped hourglass and has a rounding fillet in the corner. This fillet softens the geometric discontinuity at the corner and would probably reduce the peak shear stress. However, the thickness of the fillet means that the fillet must consist of the very brittle, multiphasic braze material, and even if the peak shear stress is reduced, the effect of a large cyclic stress on a brittle material (which is probably laced with small flaws) is considered deleterious. Modelling the material stress-strain behavior as bilinear introduces some approximation, but this is more than compensated for by the neglect of creep damage and its effect on lifetime. Creep was neglected because only a first-cycle power-up analys is was done, and no appreciable creep damage was expected. A multiple cycle shakedown period which included creep would have increased the accuracy of the strain range 
calculations, but this type of analysis is very sensitive to the loading sequence and material behavior, which are poorly defined at present.

The crack analysis was elementary. Due to the use of symmetry lines, the crack modelled was simultaneously releasing the hourglass from both tubes flanking it, an occurrence that would not be expected in actual operation. The crack analysis did show that as the crack proceeded inward, a certain section of the cracked area was under no transverse stress. The thermal analysis did not assume that the crack affected the thermal transmission between the hourglass and the tube. However, the lack of a transverse stress may indicate that a thermal contact resistance not included in the analysis was present across part of the crack, resulting in increased thermal and hence strain energy in the hourglass and accentuating the peak stress at the crack tip. The temperature difference between the hourglass and the tube wall also occurs in the longitudinal direction, creating axial shear stresses and a mode III crack propagation problem that was not analyzed. Therefore, the effect of a crack on the stresses surrounding it is probably worse than calculated, i.e., the stresses at the crack tip are probably higher. 


\section{APPENDIX--EXAMPLES OF GRAPHICAL RESULTS}

Some examples are given of the graphical results of the thermal and structural finite element analyses. The first five pages show the complete graphical output for the 30-mil full hourglass case under high flux. Other cases had similar graphical output. The remainder of the appendix displays some other interesting results chosen to provide insight into the problems encountered. 


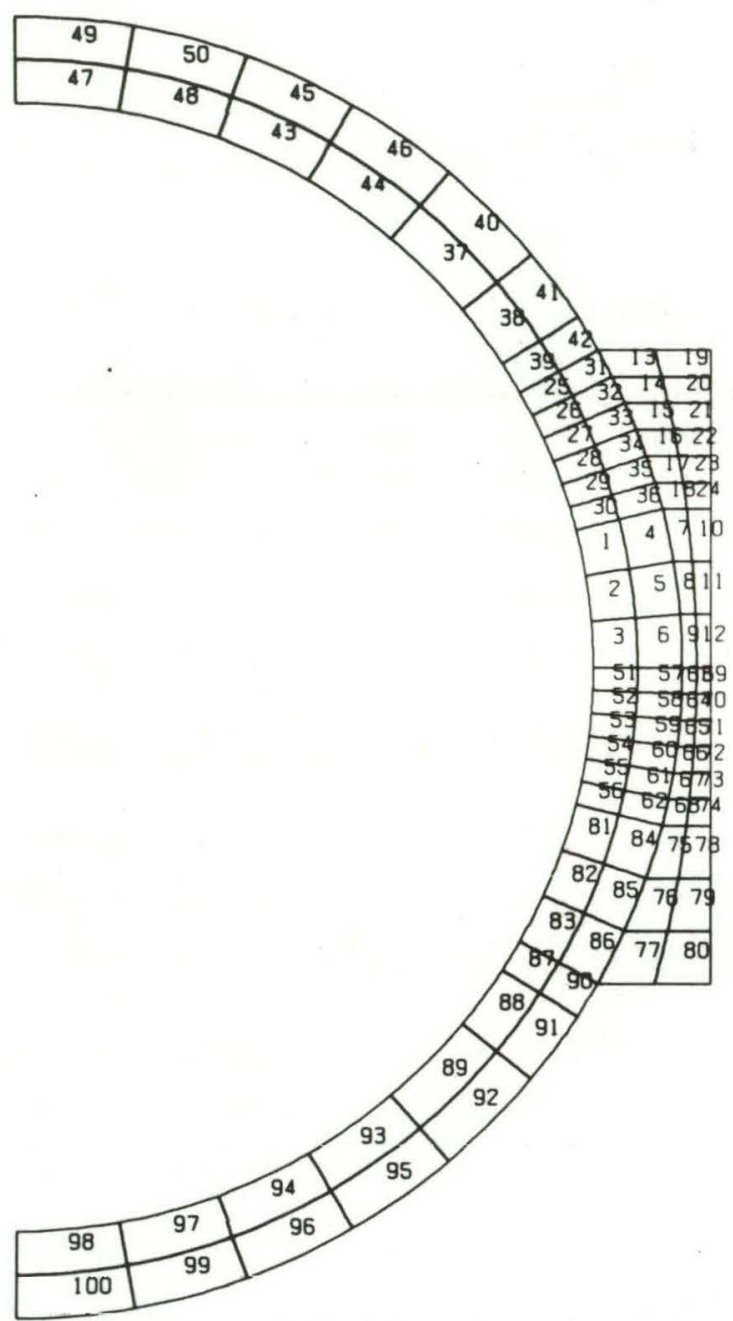

30-mil Full Hourglass Mesh

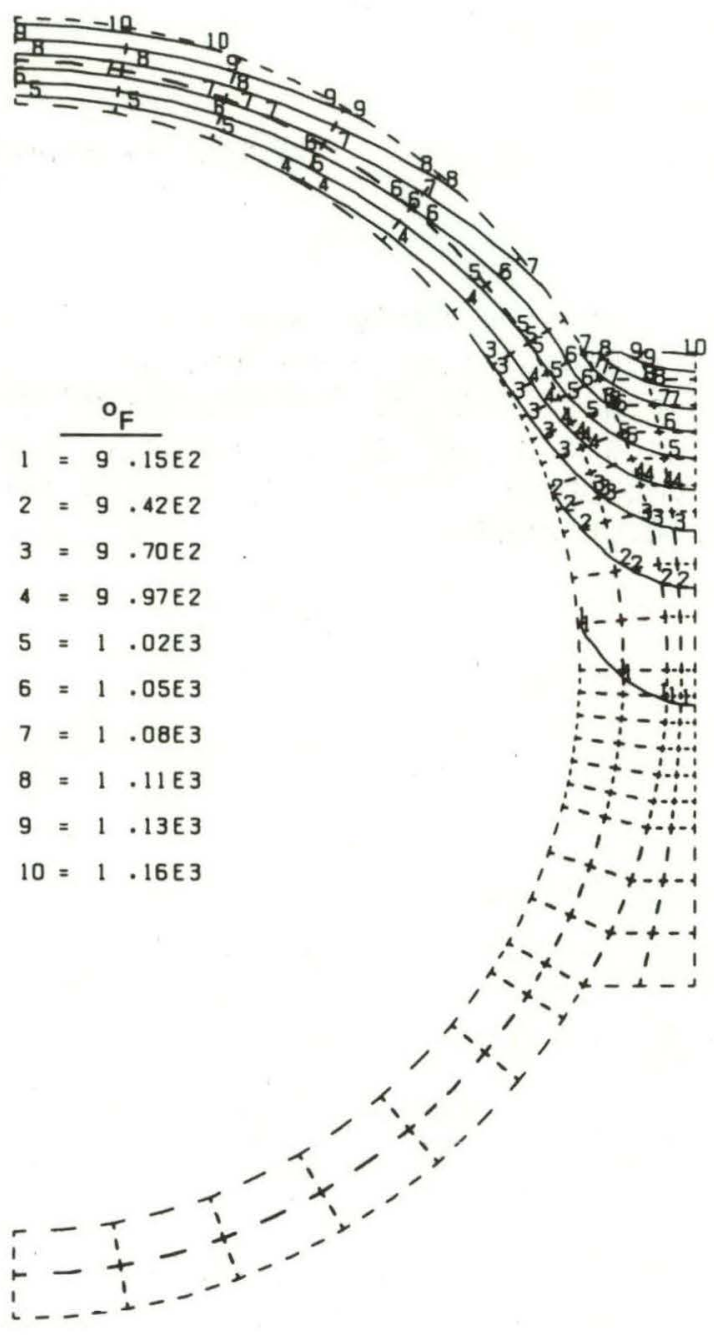

30-mil Full Hourglass

Temperatures at Height $=8.28 \mathrm{ft}$ 


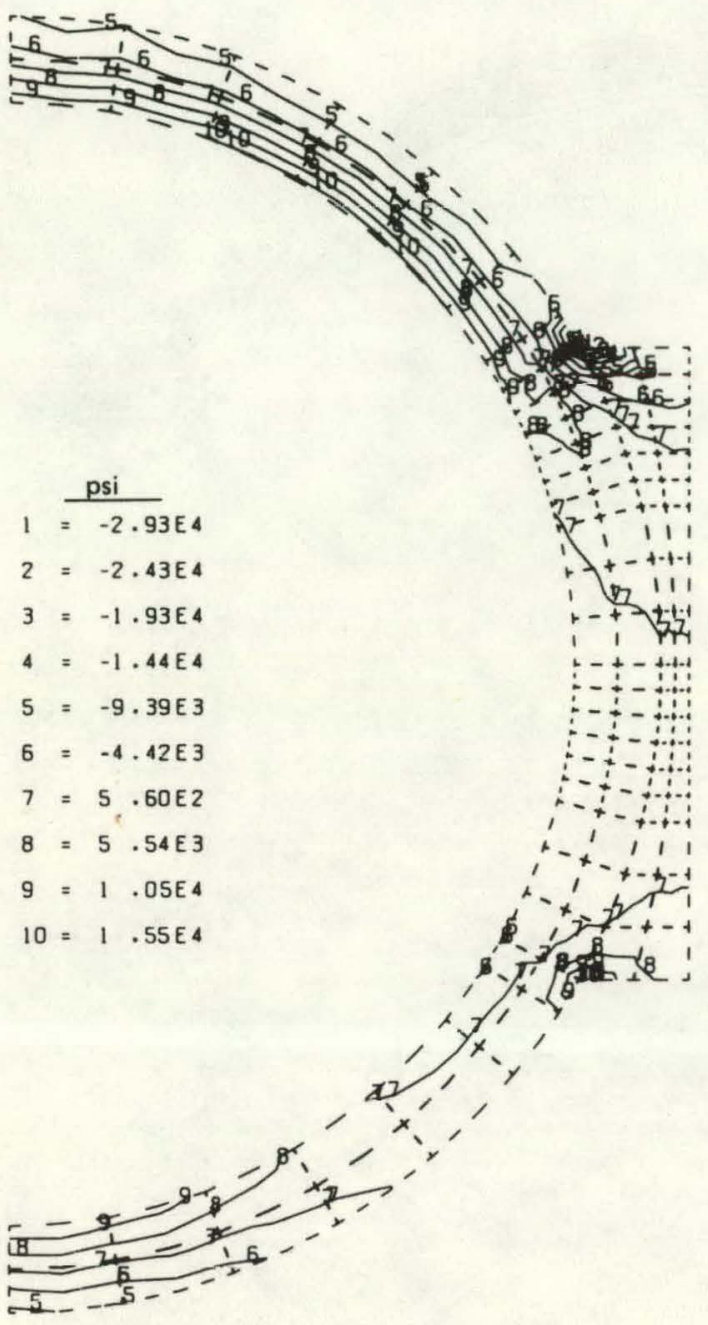

30-mil Full Hourglass

$X X$ Stress at Height $=8.28 \mathrm{ft}$

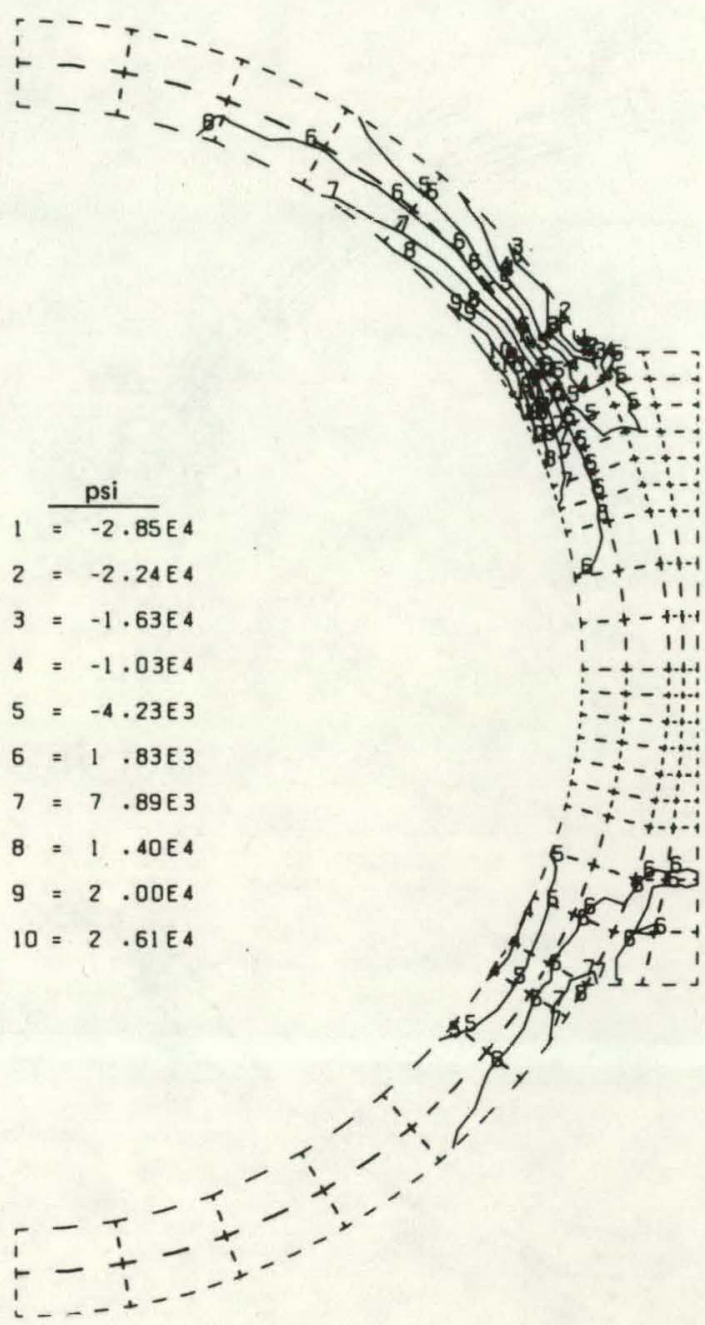

30-mil Full Hourglass

YY Stress at Height $=8.28 \mathrm{ft}$ 


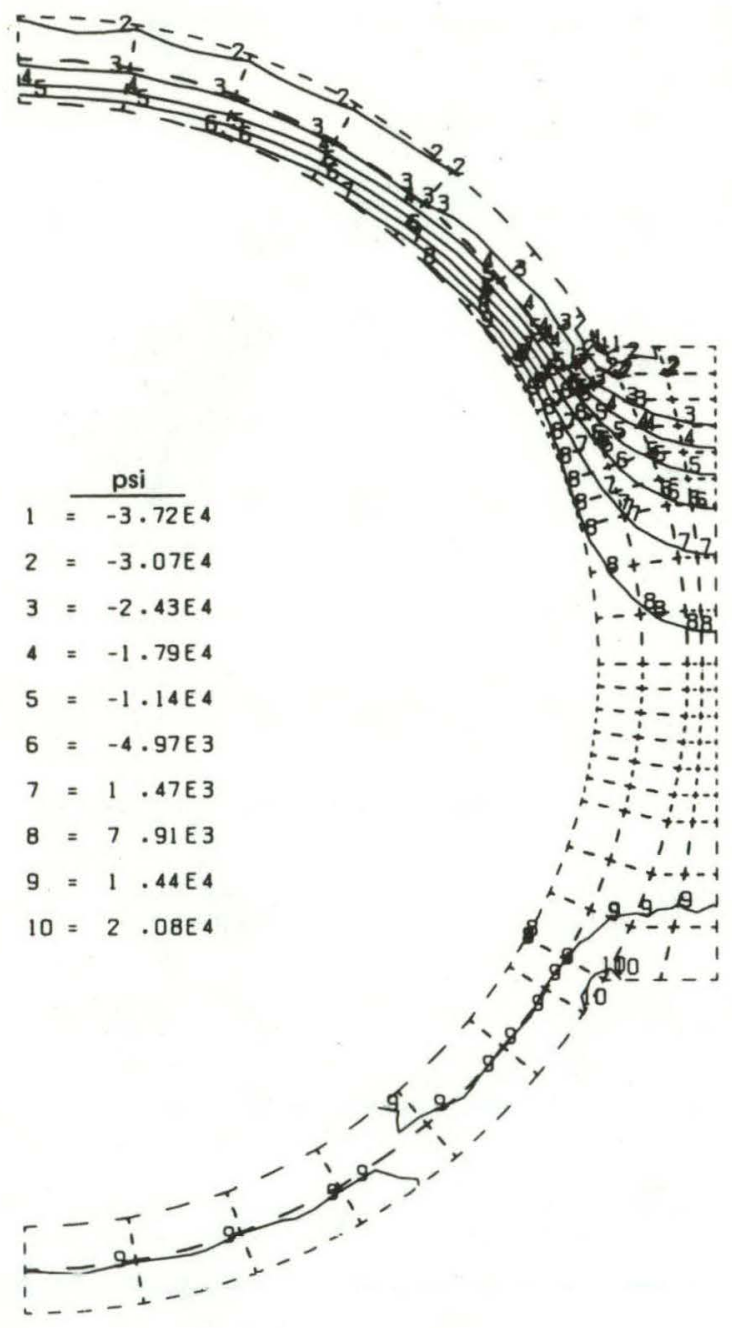

30-mil Full Hourglass

ZZ Stress at Height $=8.28 \mathrm{ft}$

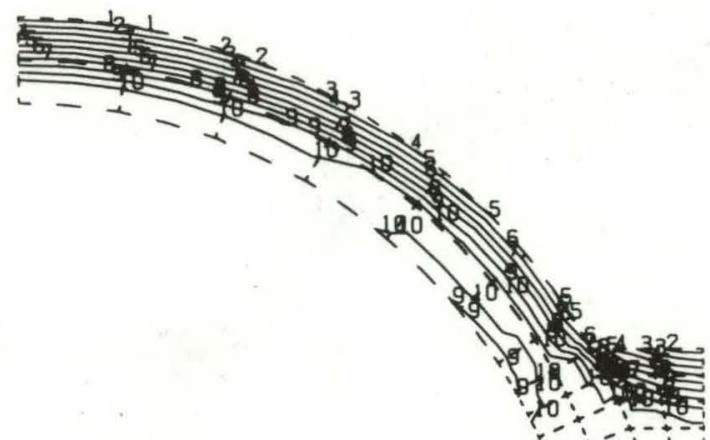

$1=\frac{\text { in./in. }}{1=-9 \cdot 73 E-4}$

$2=-8.67 E-4$

$3=-7.61 E-4$

$4=-6.55 E-4$

$5=-5 \cdot 49 E-4$

$6=-4 \cdot 43 E-4$

$7=-3 \cdot 37 E-4$

$8=-2 \cdot 31 \mathrm{E}-4$

$9=-1 \cdot 25 E-4$

$10=-1 \cdot 91 E-5$

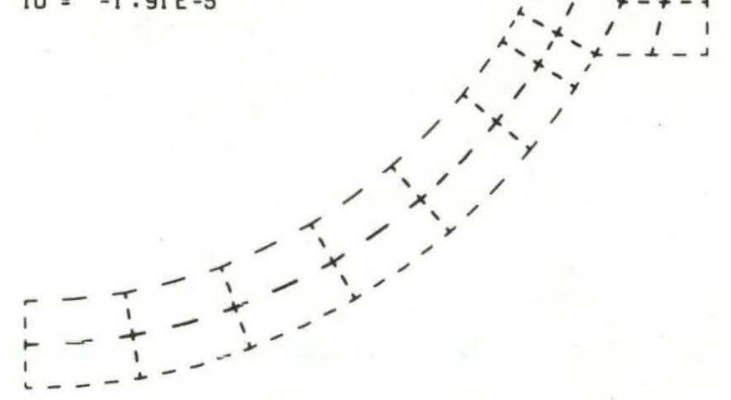

30-mil Full Hourglass ZZ Plastic Strain at Height $=8.28 \mathrm{ft}$ 


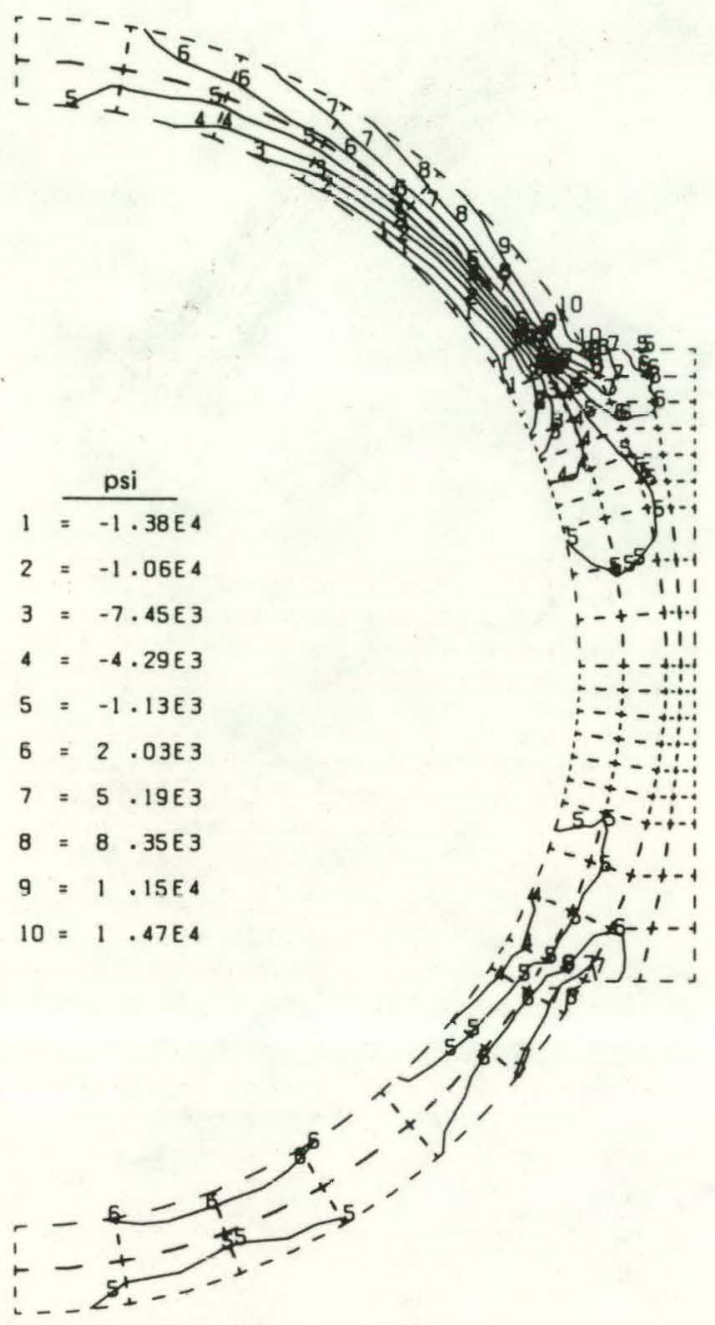

30-mil Full Hourglass

$X Y$ Stress at Height $=8.28 \mathrm{ft}$

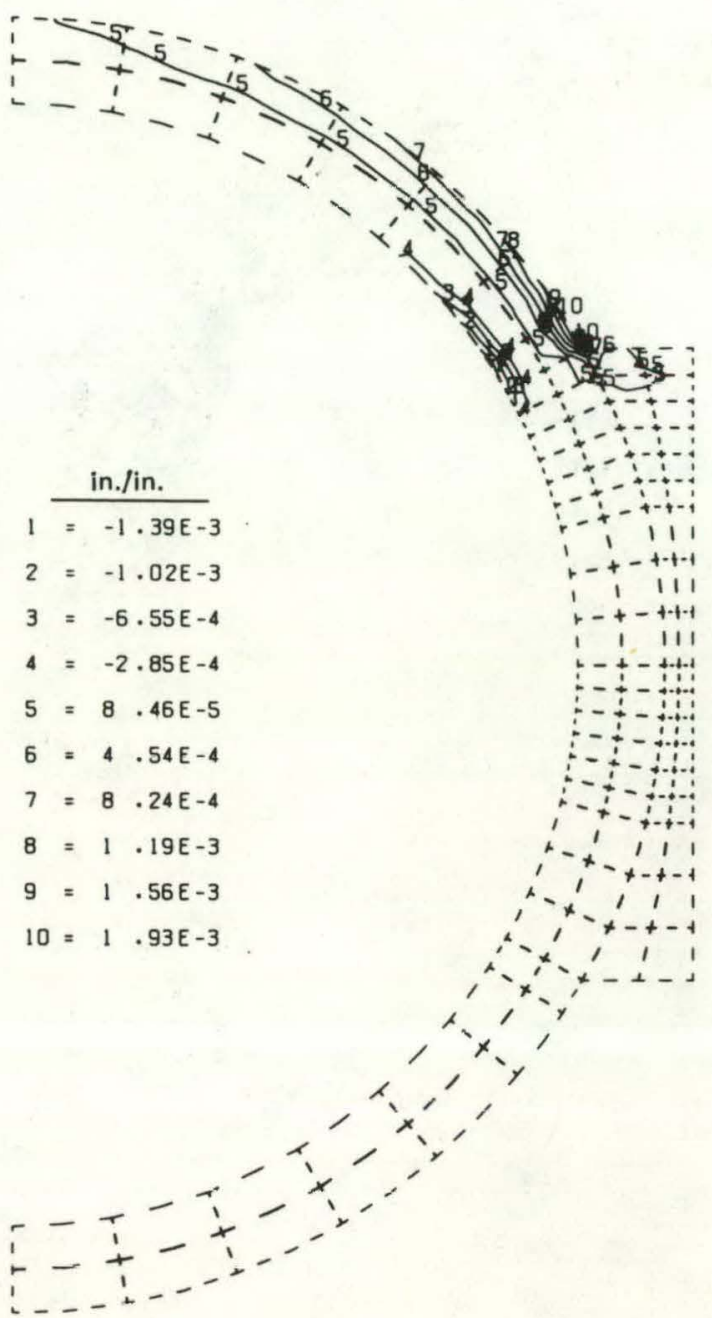

30-mil Full Hourglass XY Plastic Strain dt Height $=8.28 \mathrm{ft}$ 


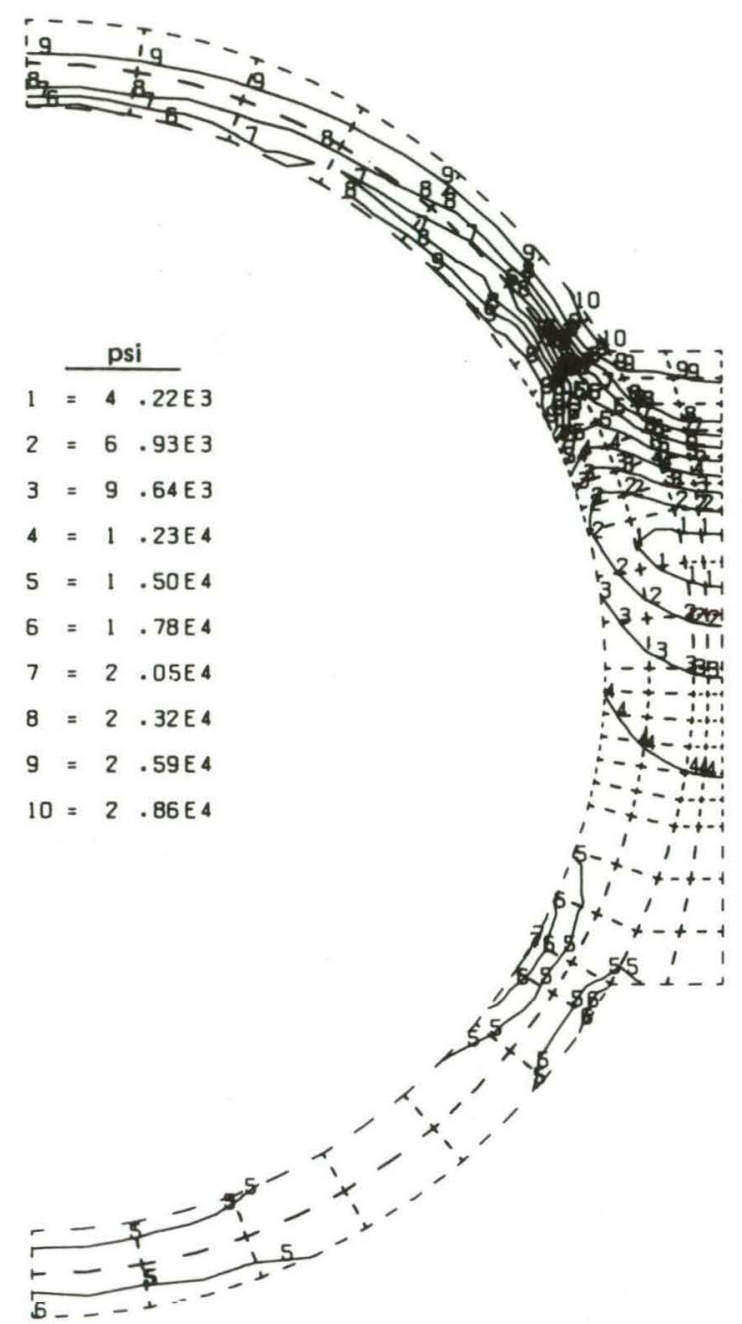

30-mil Full Hourglass

Effective Stress at Height $=8.28 \mathrm{ft}$

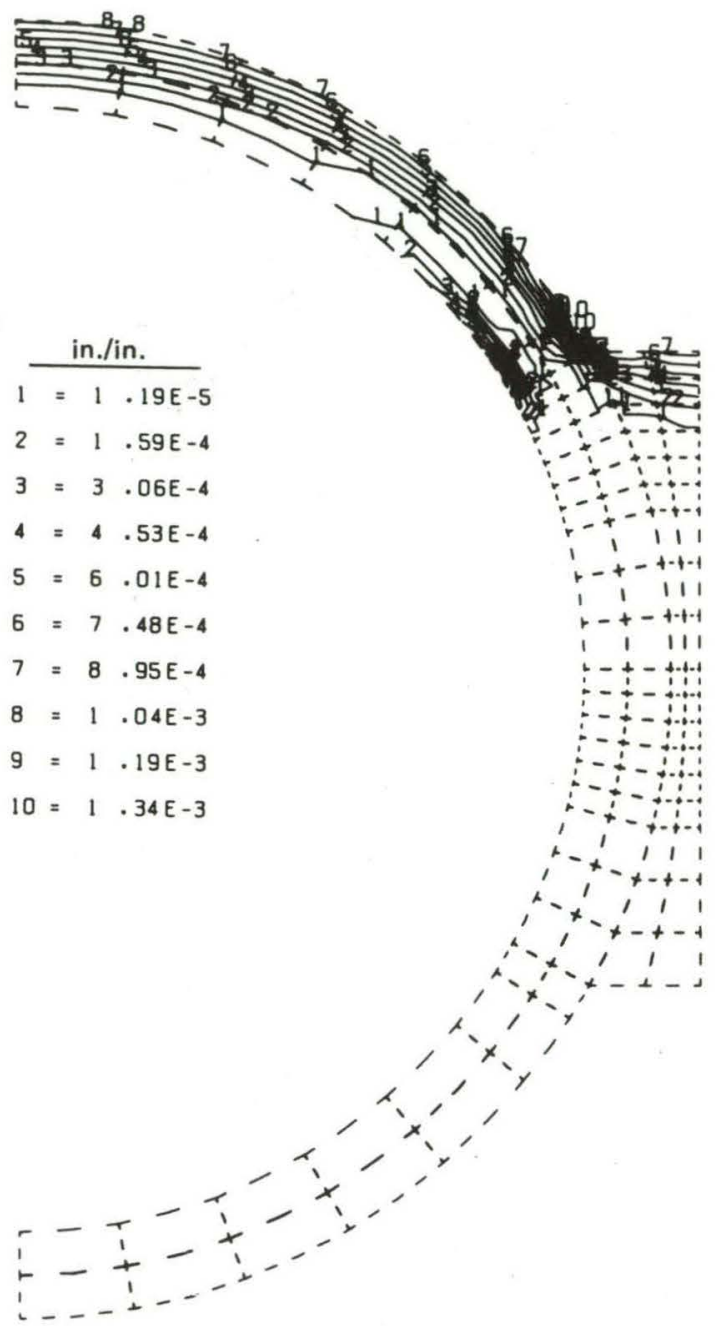

30-mil Full Hourglass

$X Y Z$ Equivalent Plastic Strain at Height $=8.28 \mathrm{ft}$ 


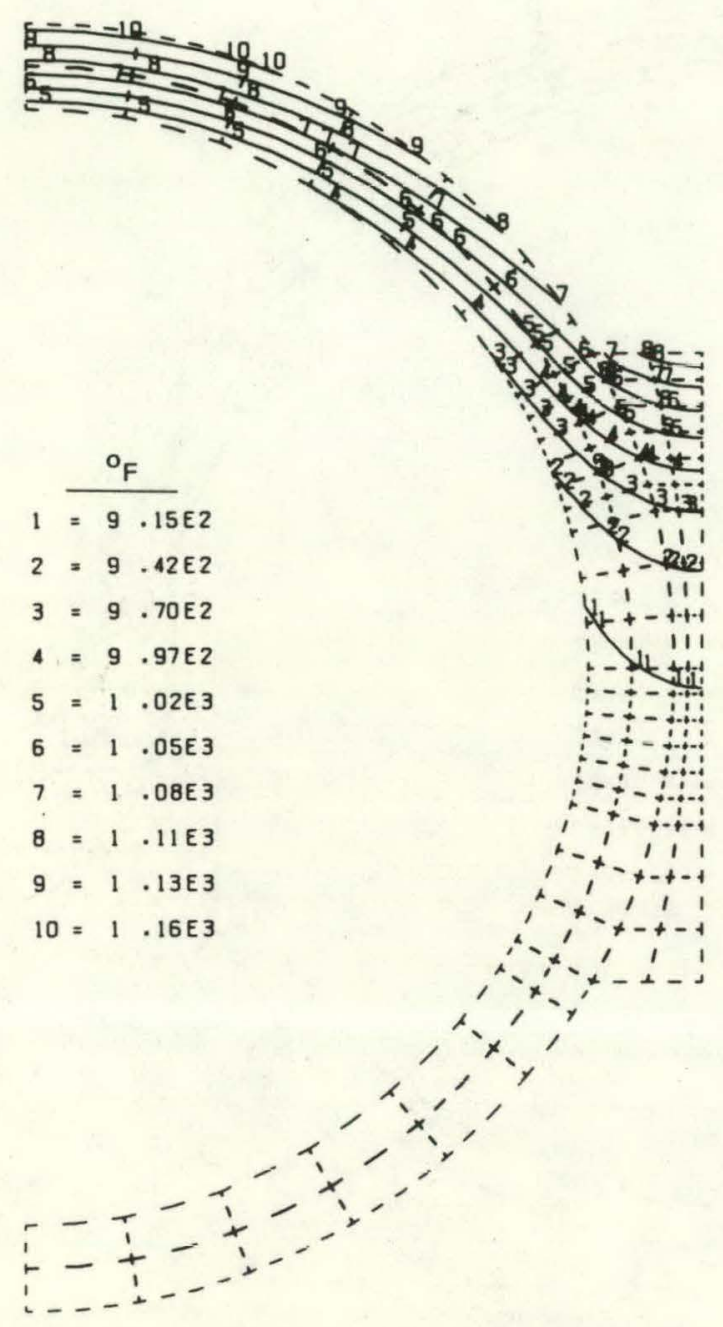

30-mil Full Hourglass/Diffuse Flux Temperatures at Height $=8.28 \mathrm{ft}$

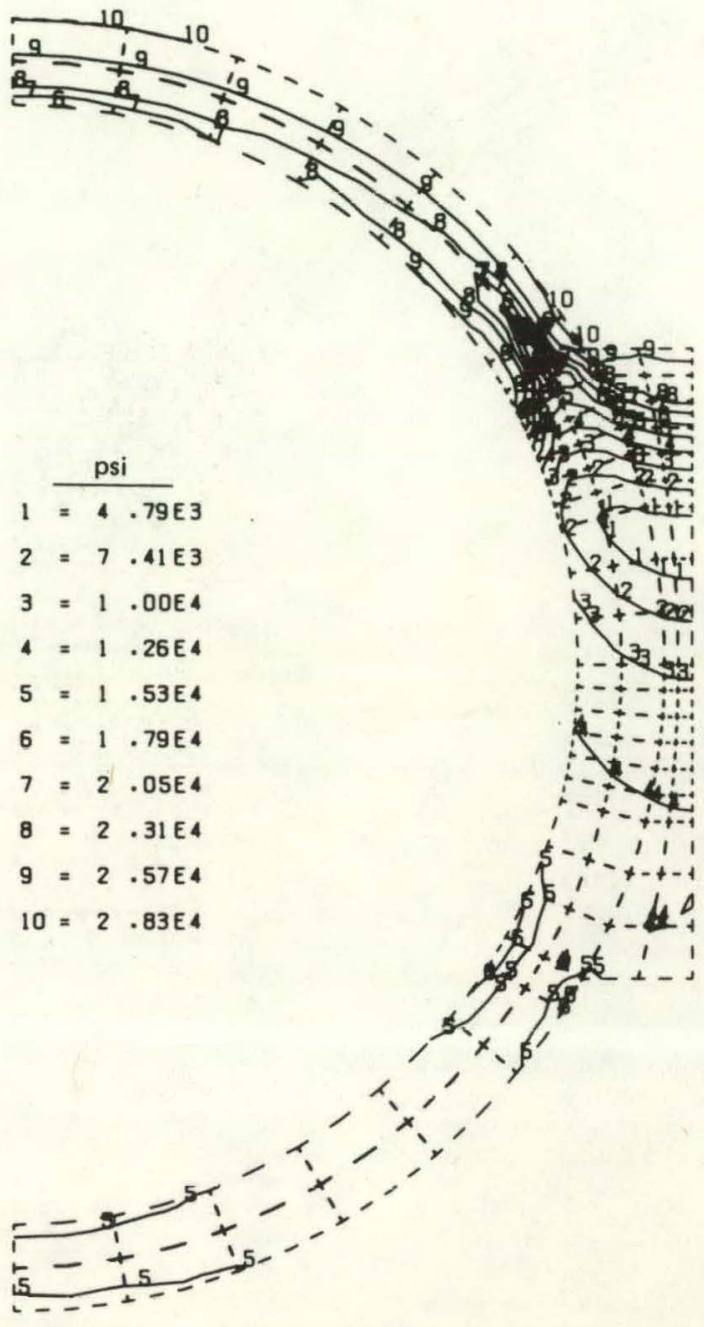

30-mil Full Hourglass/Diffuse Flux Effective Stress at Height $=8.28 \mathrm{ft}$ 


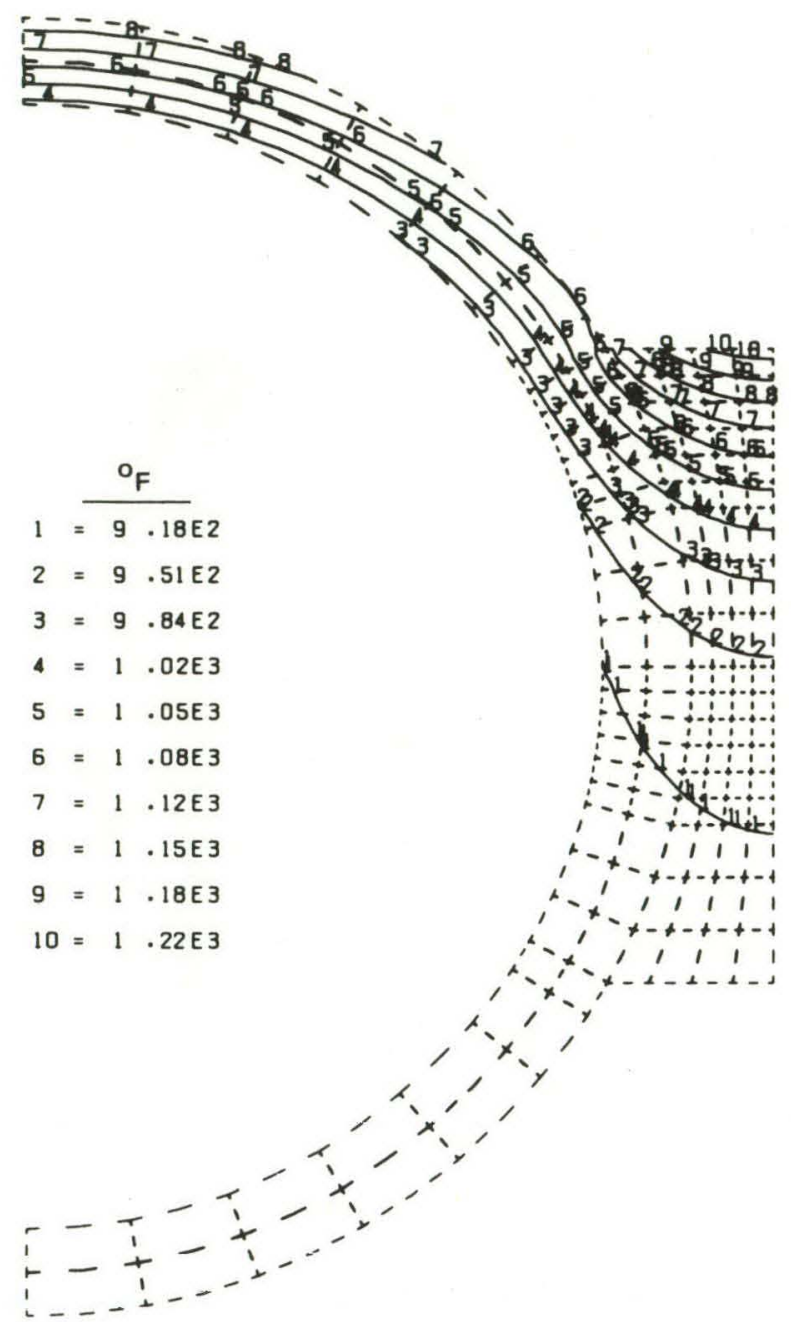

90-mil Full Hourglass

Temperatures at Height $=8.28 \mathrm{ft}$

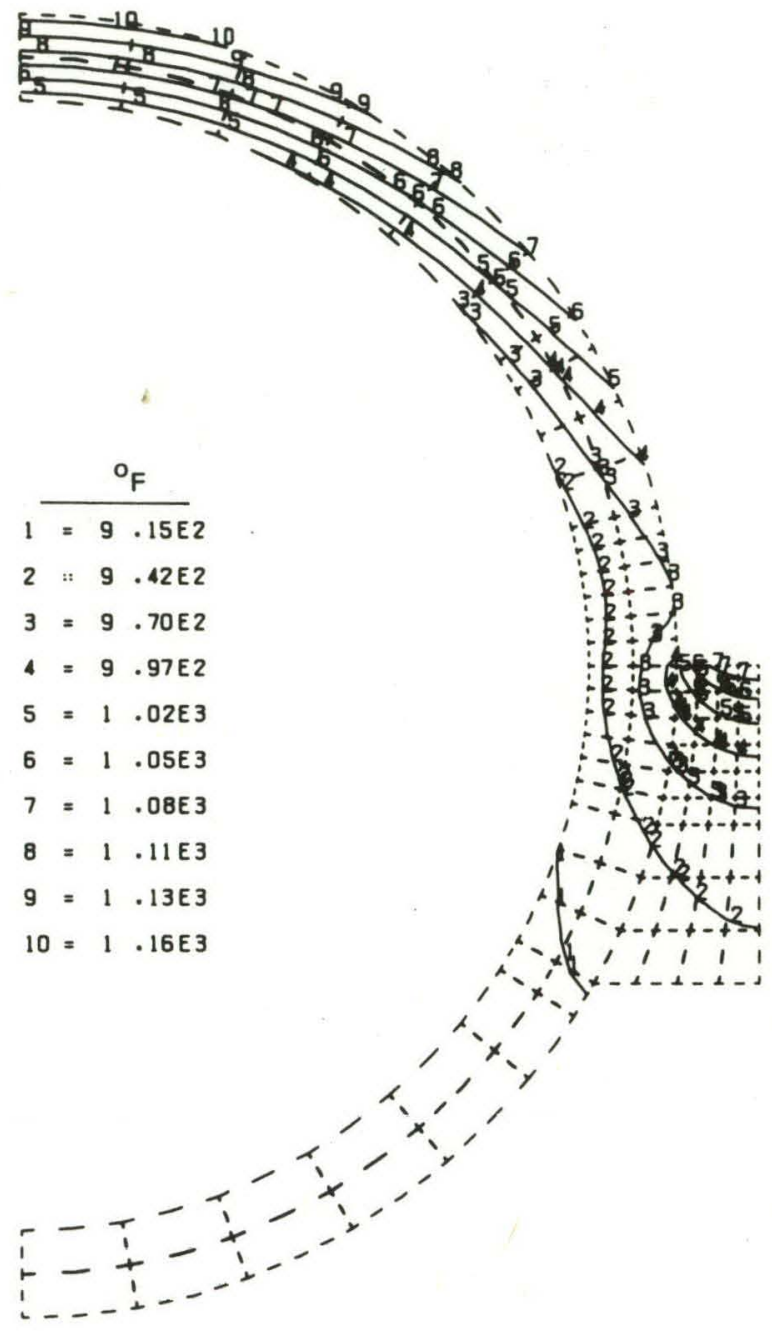

90-mil Half Hourglass

Temperatures at Height $=8.28 \mathrm{ft}$ 


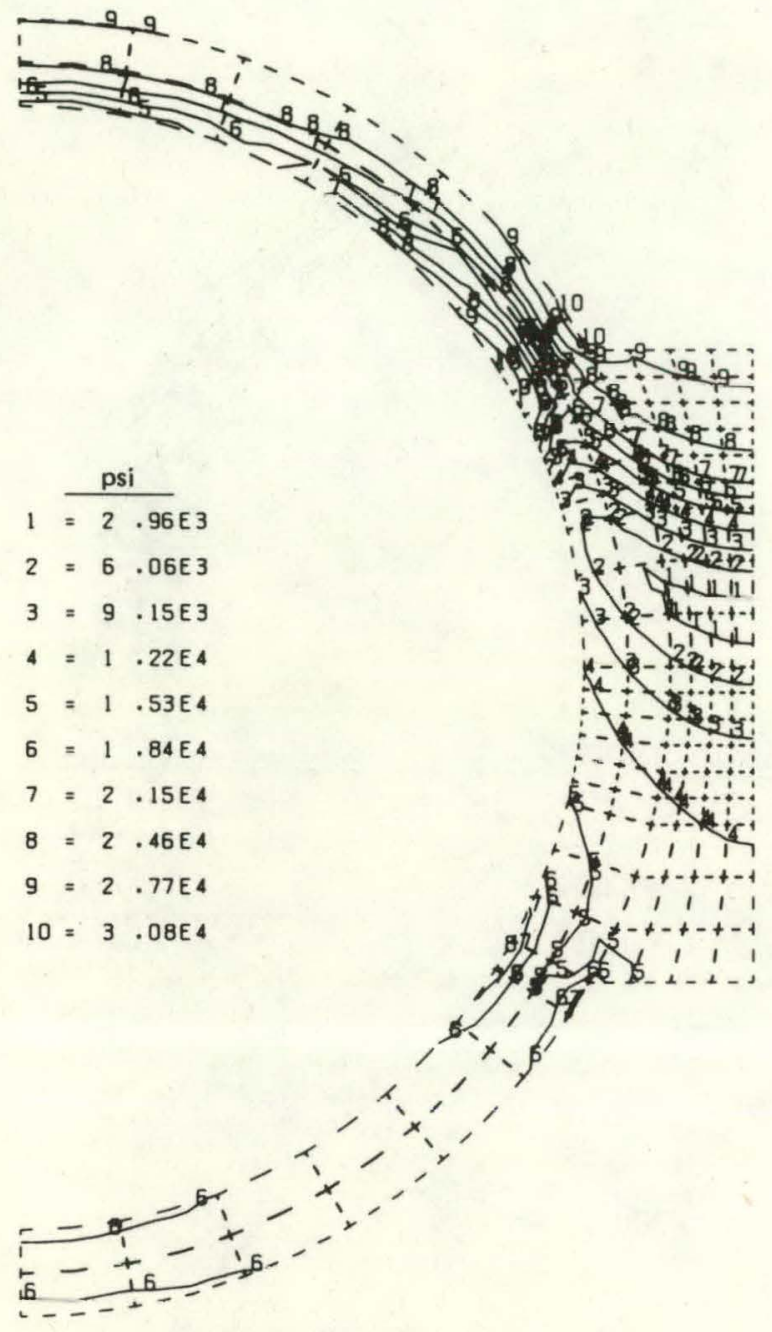

90-mil Full Hourglass

Effective Stress at

Height $=8.28 \mathrm{ft}$

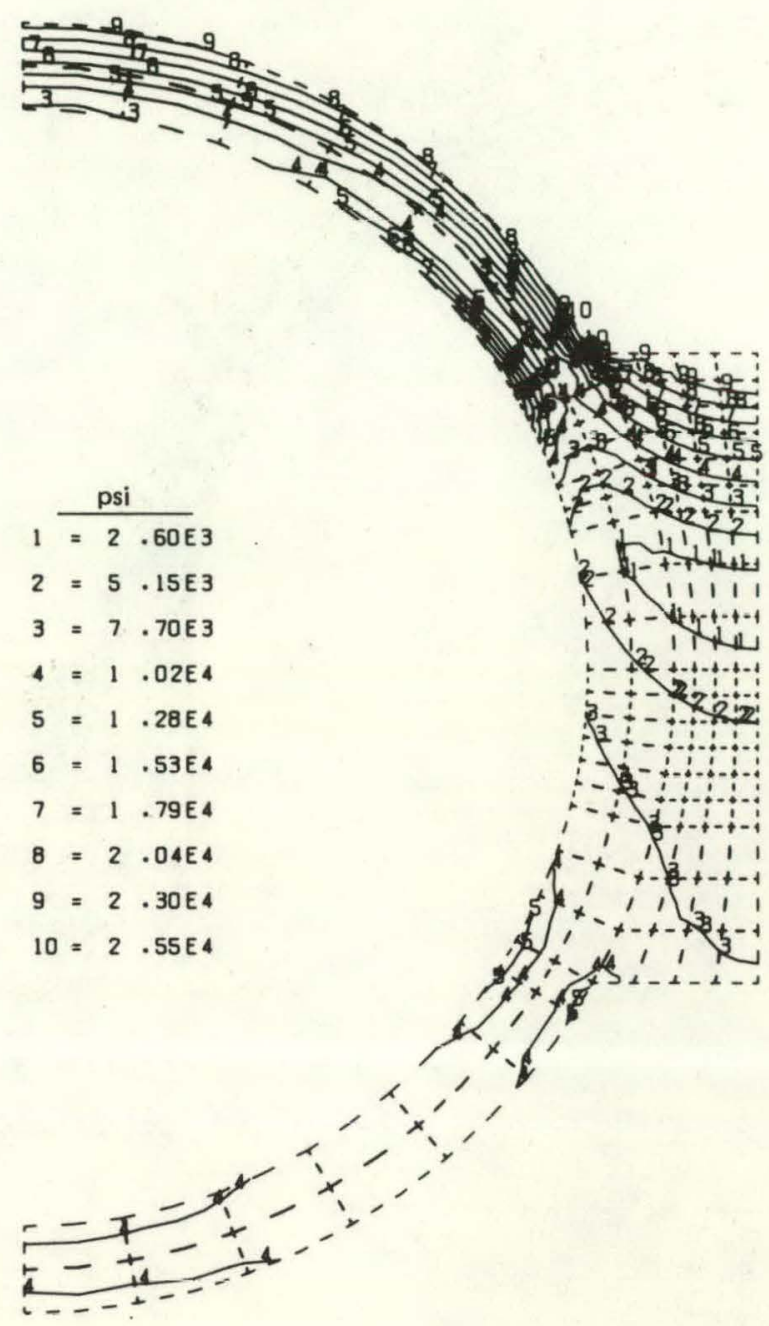

90-mil Full Hourglass--Low Flux tffective Stress at Height $=8.79 \mathrm{ft}$ 


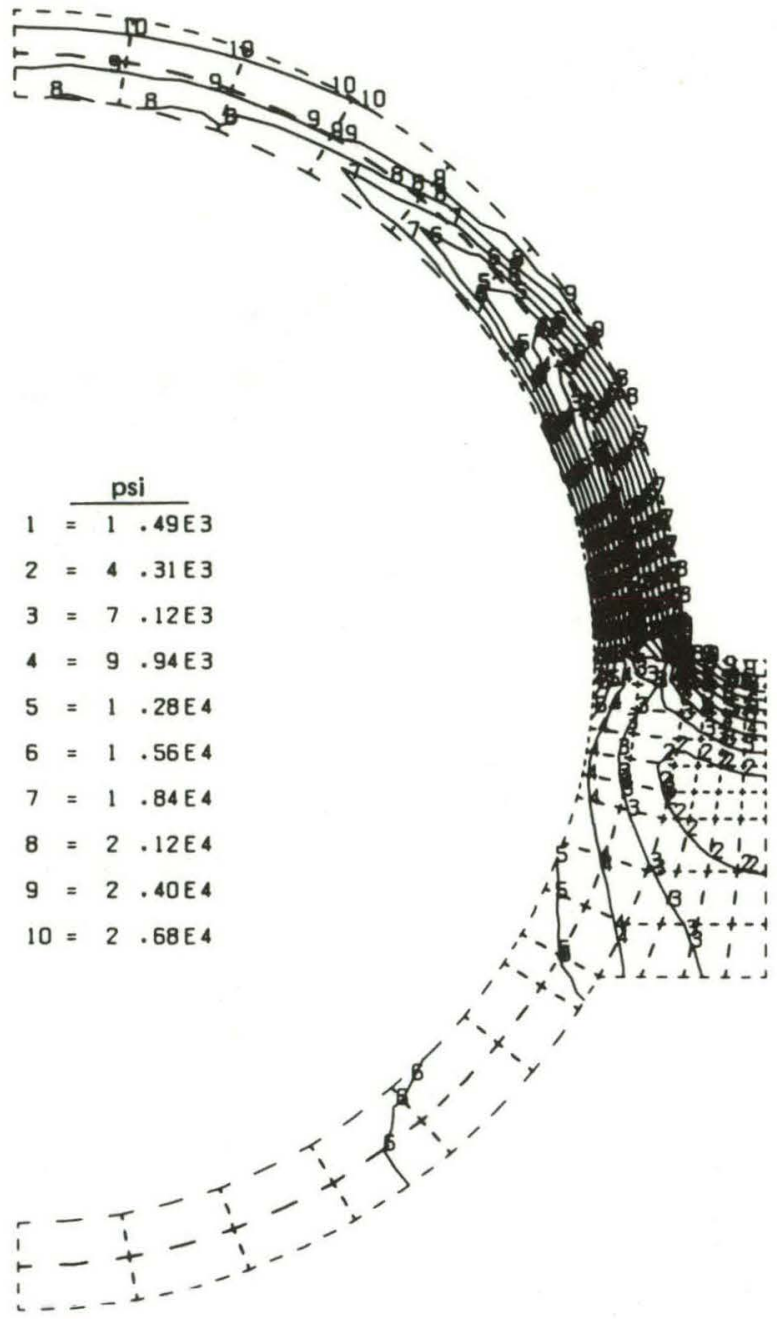

90-mil Half Hourglass

Effective Stress at

Height $=8.28 \mathrm{ft}$

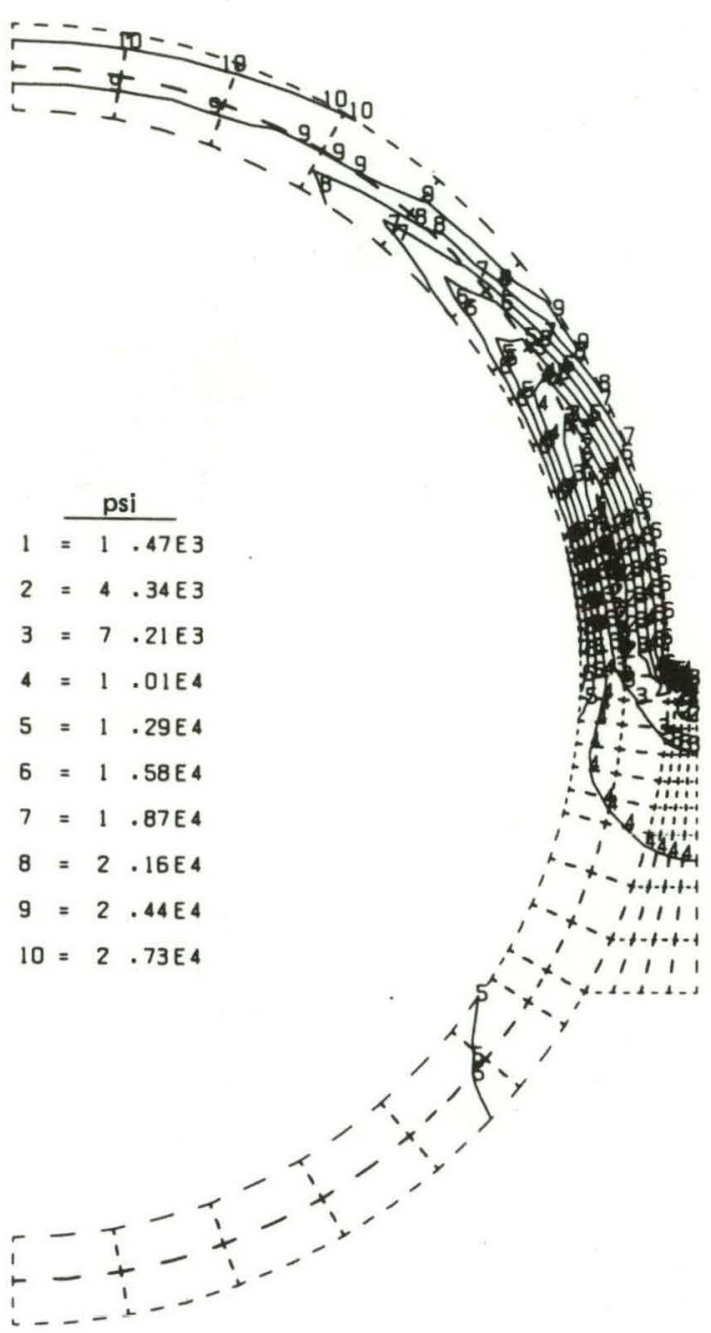

30-mil Half Hourglass

Effective Stress at

Height $=8.28 \mathrm{ft}$ 


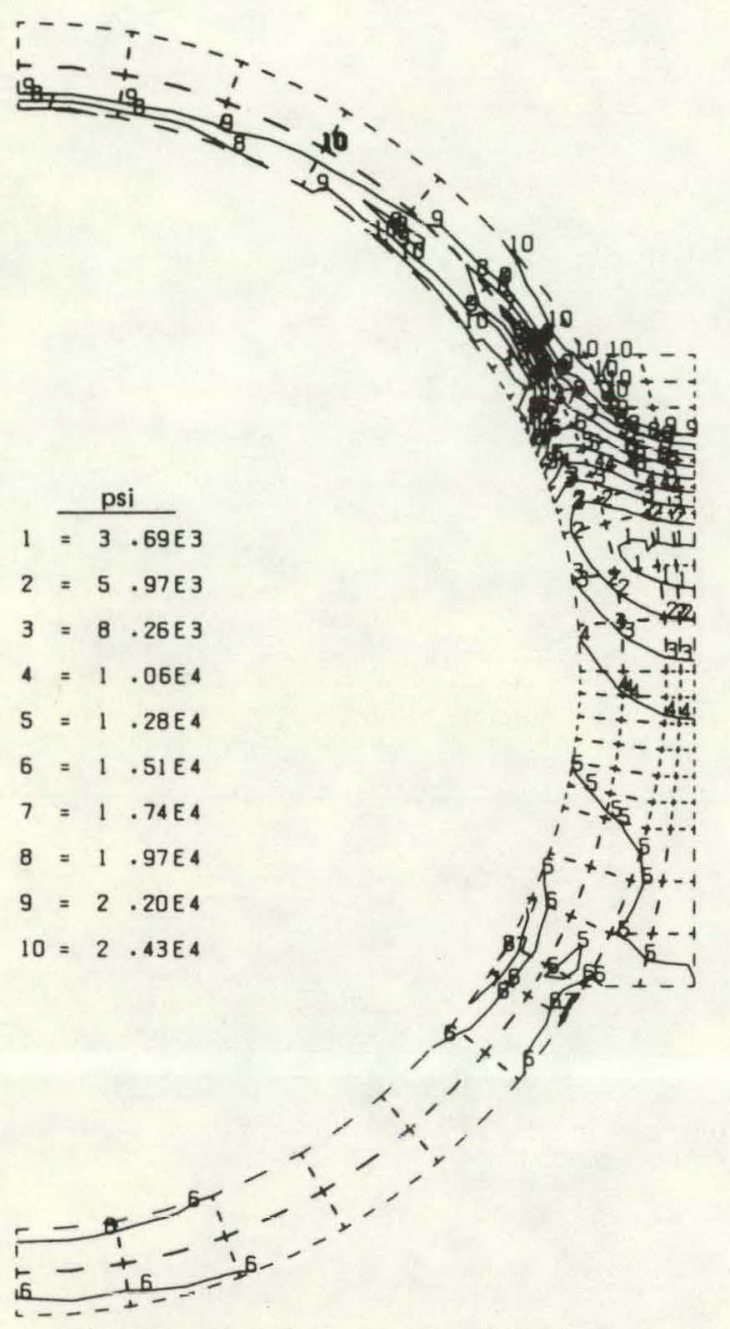

30-mil Full Hourglass/Reduced Work Hardening Slope. [ffective Stress at Height $=8.28 \mathrm{ft}$

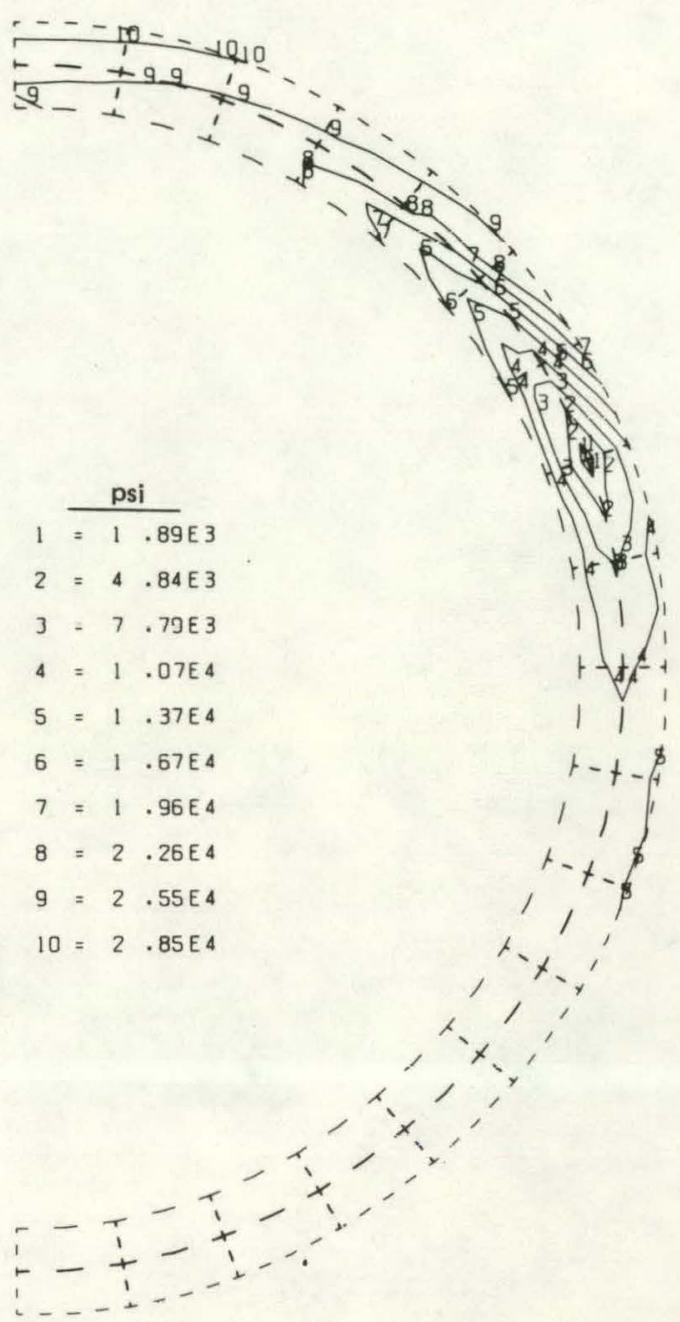

Tube Only

Effective Stress at Height $=8.28 \mathrm{ft}$ 


\section{REFERENCES}

1. J. Jones, "Effects of Bending on the Fatigue Life of Solar Receiver Tubes Subjected to One-Sided Heating," Sandia National Laboratories, Livermore, SAND78-8038, 1978.

2. "MARC General-Purpose Finite-Element Program--User Information Manual," MARC Analysis Research Corporation, Palo Alto, CA, 1980.

3. W. E. Mason, Jr., "TACO--A Finite-Element Heat Transfer Code," Lawrence Livermore National Laboratory, UCID-17980, Rev. 1, February 1980.

4. P. S. Maiya, in Inelastic Behavior of Pressure Vessel and Piping Components, Series PVP-PB-028, edited by T. Y. Chang and E. Krempl (ASME, New York, NY, 1978).

5. Case of the ASME Boiler and Pressure Vessel Code: N-47-15 (1592-15), American Society of Mechanical Engineers, New York, NY, 1979. 
UNL IMITED RELEASE

\section{INITIAL DISTRIBUTION}

\section{U.S. Department of Energy \\ 600 E Street NW \\ Washington, D. C. 20585 \\ Attn: G. W. Braun \\ K. T. Cherian \\ J. E. Rannels}

Sol ar Energy Research Institute

1617 Cole Boulevard

Golden, Colorado 80401

Attn: C. Bi shop

D. Feasby

B. P. Gupta (3)

R. Ortiz (Library)

T. B. Cook, 8000; Attn: A. N. Blackwell, 8200

B. F. Murphey, 8300

L. Gutierrez, 8400

D. M. 01 son, 8100; Attn: J.F. Barham, 8110

J. L. Wirth, 8150

R. D. Cozine, 8160

W. E. Alzheimer, 8120; Attn: G. A. Benedetti, 8121

C. S. Hoyle, 8122

B. Kistler, 8122

L. Napol itano, 8122 (10)

W. A. Kawahara, 8123

W. D. Zinke, 8123

R. J. Gallagher, 8124 (5)

M. Kanouff, 8124 (5)

J. R. Spingarn, 8314

A. J. West, 8314

S. Johnson, 8425

L. Tallerico, 8425

R. C. Wayne, 8430

C. S. Selvage, 8450

A. C. Skinrood, 8452

E. T. Cul1, 8453 (5)

D. B. Dawson, 8453

W. C. Peila, 8453 (5)

W. G. Wilson, 8453

Publications Division, 8256, for TIC (27)

Publications Division, 8256/Technical Library Processes Division, 3141

Technical Library Processes Division, 3141 (3)

M. A. Pound, 8214, for Central Technical Files (3) 


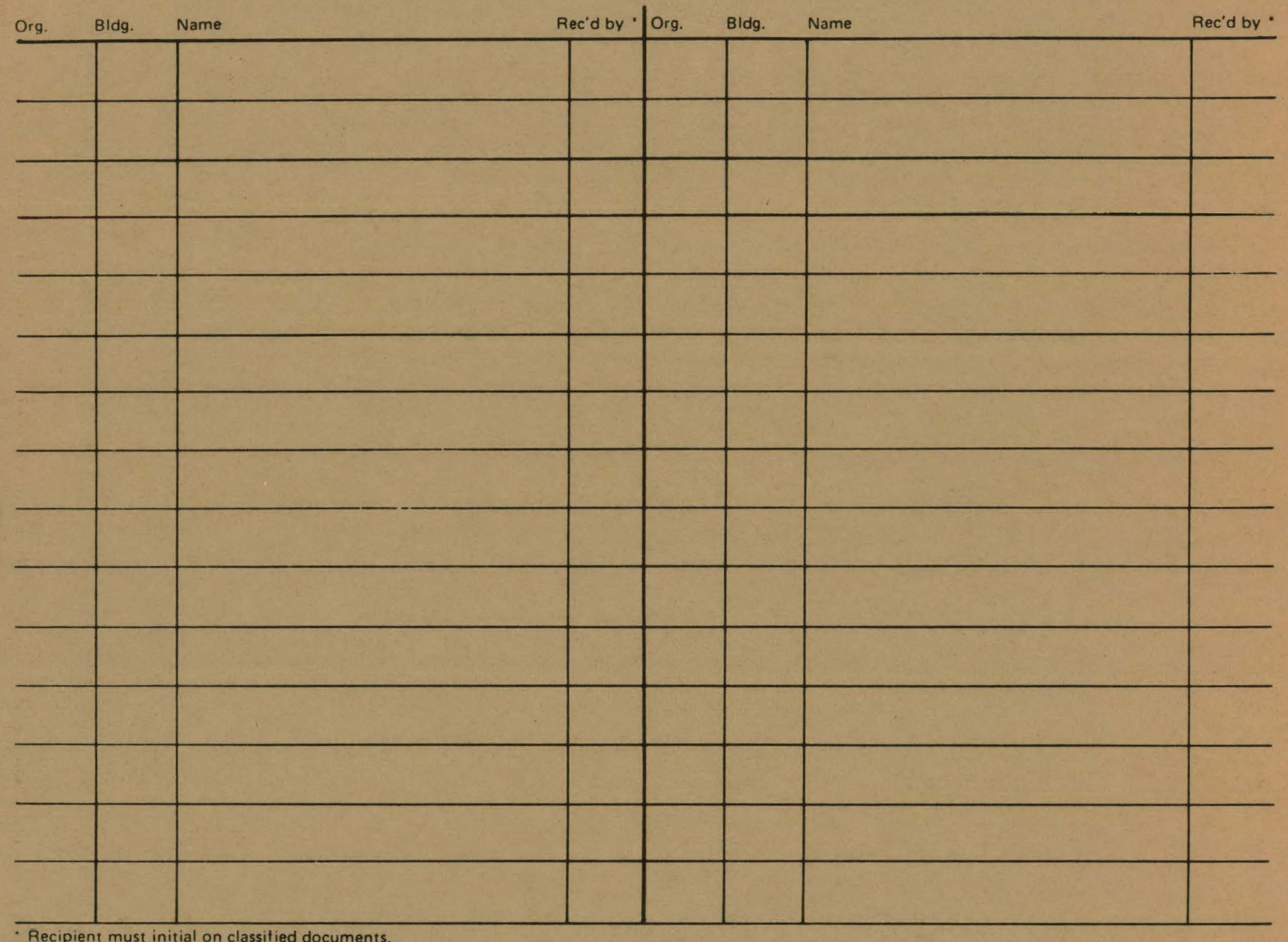

- Recipient must initial on classitied documents. 